\title{
Diffusion Imaging of Brain Tumors
}

\author{
Stephan E. Maier ${ }^{\dagger}$, Yanping Sun ${ }^{*}$, and Robert V. Mulkern $†, \ddagger$ \\ tDepartment of Radiology, Brigham and Women's Hospital, Harvard Medical School, Boston, MA, \\ 02115 \\ *Department of Radiology, University of Massachusetts Medical School, Worcester, MA 01655 \\ ¥Department of Radiology, Children's Hospital, Harvard Medical School, Boston, MA, 02115
}

\section{Abstract}

MR imaging offers a tremendous armamentarium of different methods that can be employed in brain tumor characterization. MR diffusion imaging has become a widely accepted method for probing the presence of fluid pools and molecular tissue water mobility. For most clinical applications of diffusion imaging, it is assumed that the diffusion signal vs diffusion weighting factor $\mathrm{b}$ decays monoexponentially. Within this framework, measurement of a single diffusion coefficient in brain tumors permits an approximate categorization of tumor type and for some tumors definitive diagnosis. In most brain tumors, when compared to normal brain tissue, the diffusion coefficient is elevated. The presence of peritumoral edema, which also exhibits an elevated diffusion coefficient, often precludes delineation of the tumor based on diffusion information alone. Serially obtained diffusion data is useful to document and even predict cellular response to drug or radiation therapy. Diffusion measurements in tissues over an extended range of b-factors have clearly shown that the mono-parametric description of the MR diffusion signal decay is incomplete. Very high diffusion weighting on clinical systems requires substantial compromise in spatial resolution. But after suitable analysis, superior separation of malignant brain tumors, peritumoral edema, and normal brain tissue can be achieved. These findings are also discussed in light of tissue-specific differences in membrane structure and the restrictions membranes exert on diffusion. Finally, measurement of the directional dependence of diffusion permits assessment of white matter integrity and dislocation. Such information, particularly in conjunction with advanced post-processing, is considered immensely useful for therapy planning. Diffusion imaging, which permits monoexponential analysis and provides directional diffusion information, is performed routinely in brain tumor patients. More advanced methods require improvement in acquisition speed and spatial resolution to gain clinical acceptance.

\section{Keywords}

Brain Tumor; White Matter; Gray Matter; Edema; Diffusion; Biexponential; Stretched Exponential; Kurtosis; Anisotropy

\section{Introduction}

Optimal surgical or radiation therapy of brain malignancies hinges on the exact knowledge of the spatial extent of tumor growth. Thus, the main purpose of any non-invasive imaging method applied to brain tumor diagnosis lies primarily in the tumor localization,

Address for Correspondence: Stephan E. Maier, MD, PhD, Radiology (MRI), Brigham and Women's Hospital, Harvard Medical School, 75 Francis Street, Boston, MA 02115, Tel: 617 - 732-5065, Fax: 617 - 264-5275, stephan@ bwh.harvard.edu. 
determination of tumor extent and detection of brain tissue infiltrated by tumor. Also of great interest are the correct identification of tumor related reversible changes in normal brain tissue, such as edema and dislocation. This knowledge is critical to achieve a favorable treatment outcome with minimal damage to important functional structures. Finally, information about tumor type, malignancy grade, and the presence of necrosis is useful to determine the most suitable and effective treatment procedures. Geometric information by itself may already permit a correct diagnosis of tumor type, but often an invasive biopsy, which can be obtained during surgical treatment, is required to reach a final diagnosis regarding tumor type and malignancy grade and to make a prognosis. MR offers an entire palette of imaging contrasts and quantitative parameters that is continuously evolving and improving and may ultimately permit complete and detailed diagnosis of brain tumors. The potential advantage of advanced MR imaging methods is that they could permit more uniform sampling than heterogeneous biopsies and that they can be applied repeatedly to monitor therapy success. Presently, clinical routine MRI characterizes brain tumors primarily by their appearance on $\mathrm{T}_{1}$-weighted images before and after contrast enhancement and on $T_{2}$-weighted images. In brain tumors, the mechanism of $T_{1}$-weighted enhancement after paramagnetic contrast agent injection is known to be due to a local breakdown of the blood-brain barrier. However, tumor growth is not always associated with a leaking bloodbrain barrier and the contrast agent enhancement is not specific; it could be due to tumor tissue itself, inflammation, increased permeability of blood vessels, or other abnormal changes. Other MR imaging contrasts provide information about the presence of fluid pools (diffusion imaging [1] and fluid-attenuated inversion recovery [FLAIR] [2]), vasculature and blood flow (perfusion [3], dynamic contrast enhanced (DCE) [4] and susceptibility-weighted [5] imaging), metabolic properties of the tissue (spectroscopic imaging [6]), and molecular mobility within the tissue (diffusion [7], magnetization transfer [8], and chemical exchangedependent saturation transfer [CEST] imaging [9]). Compared with conventional contrastenhanced $\mathrm{T}_{1}$-weighted spin-echo imaging and fast spin-echo $\mathrm{T}_{2}$-weighted imaging, these methods typically require longer scan times and advanced post-processing and produce images with lower spatial-resolution and/or signal-to-noise ratio, and in some cases inferior geometric accuracy. For clinical routine diagnostic imaging, typically only a selection of these advanced MR imaging probes can be applied. Nevertheless, together with the morphological information, primarily obtained with conventional imaging, these methods permit a more comprehensive diagnosis and are also useful for treatment monitoring.

The fundamental diffusion principles described in this article, which can be used to characterize brain tumors, are essentially unrelated to the spatial encoding method used for image data acquisition. Basically all clinical diffusion imaging sequences rely on spin-echo signal formation with balanced diffusion-encoding magnetic field gradients on each side of the refocusing radio-frequency pulse. Rectangular magnetic field gradient pulses of amplitude $G$, duration $\delta$, and with their leading edges separated by $\Delta$, produce diffusion sensitivity determined by a $b$-factor defined as:

$$
b=(\gamma G \delta)^{2}[\Delta-\delta / 3],
$$

where $\gamma$ stands for the gyromagnetic ratio of hydrogen. The preferred spatial encoding method for routine clinical diffusion imaging is based on single-shot echo-planar imaging (EPI) [10]. The main advantages of this method are the rapid acquisition of diffusion data and the inherent motion robustness. The sensitivity of single-shot EPI to magnetic field susceptibility variations, chemical shift, and eddy currents can, particularly in conjunction with inadequate shimming, result in ghosting artifacts, image distortions or complete signal loss. The artifacts are most prominent in areas near large air-filled bone structures such as the frontal and maxillary cavities or the skull base. The distortions increase proportionally 
with field strength, but can be alleviated with parallel imaging technology [11]. Increasingly, multi-shot navigated sequences $[12,13]$ are used obtain diffusion image data with minimal distortions. The longer scan times of such sequences, however, typically precludes more detailed probing of the diffusion process. The images presented in this review were obtained with line scan diffusion imaging (LSDI). With this diffusion imaging technique, individual columns are scanned in a rapid succession of motion-robust single-shot acquisitions. The data of these columns is then combined to form a complete image [14]. Although LSDI is up to a magnitude slower than single-shot EPI sequences, it produces images with minimal distortions and allows for relatively short echo times.

The gold-standard for brain tumor diagnosis is light microscopy analysis of histological tissue samples. Typically definitive diagnosis and differentiation between pathological and normal tissue is achieved by examination of cell-architecture parameters, such as cell arrangement, cell density, cell-size distribution (cell-size irregularity), and nucleus to cytoplasma size ratio. MR diffusion imaging probes water molecular diffusion over distances that correspond to typical cell sizes and this water diffusion is also impeded by membranes, i.e., structures that are an integral part of the cell-architecture. With increasing cell density, the impeding effect of membranes is expected to increase. Thus, MR diffusion imaging provides an intriguing access to information that otherwise can only be obtained by invasive light microscopy. Moreover, the unique ability of MR diffusion tensor imaging to visualize the integrity and course of white matter tracts, supports tumor delineation and the assessment of reversable changes in surrounding normal tissue. In what follows, the clinical value and potential future applications of diffusion imaging in brain tumors is discussed in detail and demonstrated with image data. All studies, of which data is presented, were conducted within the guidelines of the institutional internal review board, including written informed consent.

\section{Tissue Differentiation with Monoexponential Analysis of the Diffusion Related Signal Decay over a Normal b-Factor Range}

The typical brain tumor imaging protocol includes a diffusion tensor acquisition of one image without diffusion weighting and at least six images with diffusion-weighting along different directions. Often signal averaging is performed in order to achieve reasonable SNR at a isotropic spatial resolution of $2.5 \mathrm{~mm}$. The commonly used $b$-factor of around $1,000 \mathrm{~s} /$ $\mathrm{mm}^{2}$ for the diffusion-weighted image is mainly determined by the desire to obtain diffusion anisotropy and eigenvector maps with optimal quality, rather than lesion conspicuity on diffusion-weighted images. With this $b$-factor and with the typical magnetic field gradient and echo times employed on clinical MR systems, the average water molecule has several tens of milliseconds to diffuse and may migrate up to 10 micrometers in a random direction and is therefore likely to be hindered by the cell membrane or intracellular membranes. Apart from a minor perfusion-related deviation at $b$-factors up to $300 \mathrm{~s} / \mathrm{mm}^{2}[15,16]$, the diffusion-related signal loss over a normal $b$-factor range up to $1,000 \mathrm{~s} / \mathrm{mm}^{2}$ is largely monoexponential, i.e., the attenuation of signal $S$ can be described with a single diffusion coefficient $D$ as $S=S_{0} \exp (-D b)$, where $S_{0}$ represents the tissue signal without diffusion weighting. It should be emphasized, that any drastic changes in the diffusion observation time, for example by exploiting the stronger magnetic field gradients typically only available in small bore animal systems, may produce different tissue-specific diffusion coefficients. Because of the directional dependence of the diffusion coefficients in structures like fiber tracts, trace or mean diffusion-weighted and apparent diffusion coefficient (ADC) images are calculated. An example of a mean diffusion-weighted image and mean diffusion map of a brain tumor patient with the corresponding $\mathrm{T}_{1}$-weighted and $\mathrm{T}_{2}$-weighted images is presented in Fig. 1. 
Unlike normal white and gray matter, which for a normal $b$-factor range exhibit very similar ADC values, diffusion values observed in different tumor types are dissimilar and cover a wide range. In general, brain tumor ADC values measured over a normal $b$-factor range, clearly exceed ADC values of normal gray and white matter. This difference in diffusion, however, can rarely be gainfully applied to determine the extent of tumor growth within normal tissue, since tumors are often surrounded by edematous tissue, where diffusion is also elevated and thus difficult to distinguish from diffusion values representative for tumor. According to Morita et al [17], very high diffusion values in peritumoral edema of highgrade gliomas may reflect the destruction of the extracellular matrix ultra-structure by malignant cell infiltration. Considerable overlap between the tumor specific ranges of diffusion values in general precludes the use of ADC for a definitive diagnosis of tumor type. Representative ADC literature values for normal tissue, neuroepithelial tumors, other brain tumors including metastases, secondary changes and selected other pathologies are listed in Table 1. The most comprehensive study of brain tumor diffusion values assessed over a normal $b$-factor range was conducted by Yamasaki et al [18]. The values published by Yamasaki et al agree well with values of several other studies that were smaller in scope [19-24]. Unlike acute stroke lesions, none of the lesions features diffusion coefficients that are much lower than the mean diffusion coefficients of normal white and gray matter. For neuroepithelial tumors, it is striking how the diffusion coefficient correlates negatively with the World Health Organization (WHO) grade of the tumor. The most likely explanation for the observed correlation are the characteristic differences in cell size and nucleus to cytoplasma size ratio. In agreement with this hypothesis, other lesions with very high cell density, i.e., malignant lymphoma [20] and abscess [25], also show low diffusion coefficients, comparable to the diffusion coefficients observed in normal white and gray matter. There are several other studies that confirmed the correlation between diffusion and cell density for brain tumors both qualitatively [26,27] and quantitatively [28-30]. Moreover, the study by Lyng et al [31] found that diffusion coefficients measured within xenografts of different human melanoma cell lines also correlate with histologically determined cell density. However, this correlation can not be generalized, but is rather valid for a comparison within a specific category of tumors. For example, schwannomas are characterized by relatively high cell density, which would imply severely restricted diffusion and accordingly a low diffusion coefficient, exhibit a comparatively high diffusion coefficient. Obviously, besides cell density and the associated density of cell membranes, there are other structures, like intra-cellular membranes of the endoplasmatic reticulum that are involved in the protein production. These structures may depend on cell activity and tissue or tumor type and may exert considerable restriction to diffusion. For example, in white matter, the main reason for a rather low diffusion coefficient is the presence of densely arranged axons, where diffusion across the axonal membrane is impeded [32]. In gray matter, diffusion is mainly hindered by the neuropil, a dense tangle of dendrites, axon terminals, and glial cell processes. The elevated diffusion coefficient in tumors, on the other hand, may to some extent also be the result of edema that arises inside in the tumor [33]; One of the characteristics of brain tumors, irrespective of grade, is to produce a mass effect, which compresses the micro-circulation in the normal tissue around the lesion and alters the permeability properties of vessels, including those that feed the tumor. In addition, high grade gliomas also generate new blood vessels, which have very abnormal physiologic properties, including the peculiarity of allowing fluid from the intravascular compartment to seep through them. This occurs indiscriminately within and around the tumor. Furthermore, not all edema is vasogenic, but may also be related to failure of membrane pump systems (cytotoxic) or to transependymal movement of fluid from the ventricles.

The complete absence of cell membranes in cystic lesions and the destruction of cell membranes in necrotic brain lesions creates an environment where diffusion is virtually unhindered. Consequently, the diffusion constant is very high and easily distinguished from 
the diffusion constant of any other tissue, including tumor tissue. Large areas of necrosis can be well detected and delineated based on the elevated ADC within the tumor lesion [31]. However, due to the relatively coarse resolution of diffusion MRI, isolated spots of necrosis within viable tumor tissue are difficult to detect and are only noticeable by an overall elevated diffusion coefficient. One of the first reported diagnostic applications of diffusion imaging in brain tumors was the differentiation between extra-axial cysts and epidermoid tumors [1,34]. Although fluid attenuated inversion recovery (FLAIR) imaging is also capable of this differentiation, diffusion-weighted imaging provides better lesion conspicuity [35]. Similarly, for distinguishing cystic or necrotic tumor lesions from abscess lesions, performing diffusion imaging in addition to conventional MRI is superior to performing conventional MRI alone [36-38].

Diffusion imaging is not only relevant to differentiate among normal and different pathologic tissues, but also useful to document characteristic fluid volume changes in the intra and extra-cellular compartments that occur during non-surgical therapy of brain tumors. Analysis of changes in diffusion during different stages of therapy, preferably with the image data co-registered to pretreatment scans, permits repeated non-invasive and quantitative documentation of the response to drug [39], radiation [40], or gene therapy [41]. Tumor areas at the initial stage of treatment response present transient cell swelling or ischemia with decreased diffusion values. Tissue experiencing successful response with cell lysis or apoptosis displays a characteristic increase in diffusion, meanwhile tumor areas resistant to therapy exhibit unaltered diffusion values. Moreover, diffusion imaging at a later stage can also be used to document radiation-induced cerebral injury [42]. Thus, the use of diffusion imaging, can assist in delineating therapeutic-induced spatial heterogeneity within a tumor mass by providing information related to specific regions that are resistant or responsive to treatment [43]. It has also been demonstrated that changes observed during the first stages of therapy are an early indicator of the final treatment response [44-46] and the correct interpretation, should a tumor be unresponsive to therapy, may facilitate a timely decision for protocol adjustment or alternative therapy.

\section{Tissue Differentiation based on the non-Monoexponential Diffusion Related Signal Decay over an Extended $\boldsymbol{b}$-Factor Range}

Diffusion-weighted brain images with very high $b$-factors of $5,000 \mathrm{~s} / \mathrm{mm}^{2}$ or higher, which clearly depict tissue structures above the noise threshold, can readily be obtained on clinical scanners. Examples of such images from a brain tumor patient are presented in Fig. 2. The residual signal at very high $b$-values is distinctly higher than monoexponential extrapolation of observations performed within the normal $b$-factor range would predict $[47,48]$. Of course, compared to images acquired at a $b$-factor of $1,000 \mathrm{~s} / \mathrm{mm}^{2}$, there is an increased signal loss of up to $90 \%$ or more, which typically has to be compensated with a decrease in spatial resolution. Optimal lesion conspicuity, however, is not the only reason for such voxel size adjustment: Application of the magnitude operator for the purpose of eliminating nonuniform phase variations, changes the Gaussian distributed complex signal to a Rician distributed magnitude signal [49]. At signal levels that approach the level of noise, the Rician distribution is skewed and exhibits a bias that tends to exaggerate the departure from a monoexponential signal decay [50]. In white matter, when the gradient direction coincides with the fiber orientation, the signal loss is particularly high and an exaggeration of the nonmonoexponential decay is therefore more likely. Moreover, it should be emphasized that basic magnitude signal averaging will not eliminate the Rician signal distribution and the associated bias at low signal levels. Partially the signal loss can be attributed to the longer echo times, typically between 90 and $140 \mathrm{~ms}$, that are required to achieve higher $b$-factors within the gradient amplitude limits of clinical MR systems. Overall, for brain tissue it has been determined that there is an obvious deviation from the monoexponential diffusion, 
which represents a genuine tissue property and does not arise merely due to a partial volume effect or low SNR. For an unchanged diffusion gradient amplitude and with the assumption that the diffusion encoding gradient duration $\delta$ is only slightly shorter than the time $\Delta$ between the leading edges of the diffusion gradients, increasing the $b$-factor from $1,000 \mathrm{~s} /$ $\mathrm{mm}^{2}$ to $5,000 \mathrm{~s} / \mathrm{mm}^{2}$ entails an increment of $\delta$ by approximately $70 \%$. Accordingly, with the increased observation time, a free-diffusing water molecule travels on average $30 \%$ further and thus covers a volume twice as large. This is not a dramatic increase in diffusion distance and diffusion measurements obtained with clinical systems for the same $b$-factor range 0 $1,000 \mathrm{~s} / \mathrm{mm}^{2}$, but $\delta$ adjusted for a maximum $b$ of either $1,000 \mathrm{~s} / \mathrm{mm}^{2}$ or $5,000 \mathrm{~s} / \mathrm{mm}^{2}$ seem to agree well, although a formal comparison for different tissues has not been published. Another undesired side effect of the higher diffusion encoding is a substantial increase in motion-related phase encoding sensitivity. With single-shot sequences, uniform phase shifts due to rigid body translation have no detrimental effect. However, any rotation or nonuniform motion due to organ deformation causes intravoxel phase dispersion, which may result in an overall or localized signal loss. The phase shift $\Phi$ introduced by motion with velocity $v$ in the presence of rectangular diffusion encoding gradients of amplitude $G$, is given by:

$$
\Phi=\gamma \gamma G \delta \Delta=v \Delta \sqrt{b /(\Delta-\delta / 3)},
$$

where $\gamma$ is the gyromagnetic ratio. With diffusion gradient parameters typically used for diffusion tensor imaging on clinical MR systems, the resulting velocity sensitivity is on the order of $1 \mathrm{~mm} / \mathrm{s}$ for $360^{\circ}$ phase shift. This is high, when compared to blood-flow related deformations in the brain, which can occur with velocities in excess of $1 \mathrm{~mm} / \mathrm{s}$ [51] Highly diffusion-weighted imaging at $b=5,000 \mathrm{~s} / \mathrm{mm}^{2}$ increases the motion sensitivity by approximately threefold.

The acquisition of image data at multiple $b$-factors, permits a more detailed analysis of the non-monoexponential diffusion related signal decay. Most of the data presented in this article was obtained from measurements at 16 evenly distributed $b$-factors from 5 or 100 to $5,000 \mathrm{~s} / \mathrm{mm} 2$. Several analysis models have been proposed to describe signal decay with fitted functions. Purely empirical approaches to characterizing the non-monoexponential signal decay with $b$-factor have been forwarded [52-56], as well as more physically motivated models [55,57-60]. The empirical models include a "stretched exponential" function $S=S_{0} \exp \left(-(D b)^{\alpha}\right)$ with an additional parameter $\alpha(0<\alpha<1)$ [52], a "statistical model", which posits a truncated Gaussian distribution of diffusion coefficients spread about a mean diffusion coefficient [53], and the "kurtosis" model in which the departure from monoexponentiality is fit with a Taylor expansion of the decaying exponential with truncation of the series to a second order polynomial in $b$ with the kurtosis parameter $K$ according to $\ln (S)=\ln \left(S_{0}\right)-b D+b^{2} D^{2} K / 6$ [54,61]. Common to all three of these empirical fitting methods are two free fitting parameters and the failure to adequately represent the data as $b$-factors above $3,000 \mathrm{~s} / \mathrm{mm}^{2}$ are gathered. The biexponential fit, which can be considered purely as an empirical or as a physically motivated model, has effectively three free parameters available for fitting normalized diffusion decay curves and has proven extremely robust for characterizing data even as high $b$-factors are sampled [55]. It is often disparaged, however, for at least two reasons. The first is that even as a purely empirical fit, biexponential fitting of experimental data is a notoriously difficult mathematical task, with unique fits practically impossible to achieve [62]. The second reason for criticism is that as a physical model, a biexponential implies that the tissue voxel under consideration may contain two separate water compartments, perhaps intra- and extracellular water compartments, with a slow and a fast diffusion coefficient respectively. Countering this simple interpretation is the fact that a voxel of brain parenchyma will contain roughly $80 \%$ 
intracellular water, yet the fractional amplitude of the slow diffusion coefficient is only around $0.3[48,63]$. Attempts to modify and/or augment the intra-extracellular compartment model with separate $T_{2}$ values within the compartments, water exchange between the compartments and/or with explicit expressions for restricted diffusion within cells due to membrane barriers have all been forwarded with varying degrees of success [57-60]. As is often the case with such quantitative MR models, however, results and simulations obtained can appear quite compatible with the data without actually being validated by the data due to the large number of free parameters and assumptions employed. As such, the mystery of the departure of tissue water signal decay with $b$-factor from a purely monoexponential decay remains unsolved, though this unfortunate circumstance does not really alter its availability for tissue characterization and differentiation of healthy from pathological tissue. A more detailed discussion about different analysis models and possible interpretations was published in a review article by Mulkern et al [64].

Biexponential tissue diffusion parameters can be obtained by pixel-wise non-linear leastsquare fitting of signal intensity decay $S$ vs $b$-factor to a biexponential function of the form

$$
S=A_{f} \exp \left(-D_{f} b\right)+A_{s} \exp \left(-D_{s} b\right)
$$

where $D_{f}$ and $D_{s}$ are the diffusion coefficients of a fast and a slow diffusion component, respectively, and $A_{f}$ and $A_{s}$ are their respective sizes. The ratios $A_{f} /\left(A_{f}+A_{s}\right)$ and $A_{s} /\left(A_{f}+A_{s}\right)$ define the relative size fraction $f_{f}$ and $f_{s}$ of the fast and slow diffusion component, respectively. The quality of the fit is judged on the basis of the $\chi^{2}$ error, i.e., the sum of the unweighted squared differences between the input data points and the function values, evaluated at the same $b$-factors. This biexponential equation is valid for a single diffusion encoding direction. In the case of anisotropy, derivation of composite parameters from multiple direction measurements is not satisfactorily resolved. For example, with a monoexponential analysis, the geometric mean of the measurements along different directions can be used to derive the composite paramters. In contrast, with a nonmonoexponential analysis, geometric averaging can lead to cross terms and to amplitudes with tensor properties similar to the diffusion coefficients themselves [65-67]. Thus, the interpretation of the derived composite parameters becomes less obvious. Though the proper manner of incorporating anisotropy into non-monoexponential analysis remains unresolved, we note that for tumors, anisotropy effects, particularly in the core, tend to be small.

Representative decay curves of diffusion measurements with a single encoding direction from individual pixels in normal white matter, edema, and a glioblastoma tumor are shown in Fig. 3. Quantitative parameter values for different fits to the data can be found in Table 2. Typical biexponential diffusion parameters for normal and pathological tissues of the brain are presented in Table 3 . The cortical gray matter values listed in Table 3 were measured with a surface coil and a diffusion imaging sequence that included FLAIR to avoid any confounding partial volume effects from cerebrospinal fluid [63]. The table does not list values for cystic lesions, since the diffusion signal decay is monoexponential [7], like in pure water. For tissues, biexponential fitting results in a fast diffusion coefficient that is $\mathbf{5 0}$ to $70 \%$ higher than the diffusion coefficient obtained by monoexponential fitting over the normal $b$-factor range of 0 to $1,000 \mathrm{~s} / \mathrm{mm}^{2}$. At $b=0 \mathrm{~s} / \mathrm{mm}^{2}$ more signal stems from the fast diffusion component. At a $b$-factor of approximately $1,000 \mathrm{~s} / \mathrm{mm}^{2}$ the relative signal contribution is reversed and at $b=5,000 \mathrm{~s} / \mathrm{mm}^{2}$ the fast diffusion component contributes typically less than $1 \%$ of the overall signal. Like the monoexponential diffusion coefficient obtained by analysis over a normal $b$-factor range, the fast diffusion coefficient shows little variation between white and gray matter. Similarly, the relative size fractions for gray and white matter are also indistinguishable. The slow diffusion coefficient in gray matter, 
however, is significantly higher and the biexponential parameter manifestation of the observed reversal of contrast between gray and white matter at low vs high $b$-factors $[63,68,69]$.

For malignant brain tumors, Table 3 only shows the average values of fourteen cases (nine WHO grade IV glioblastomas, two WHO grade III astrocytomas and three metastases) [7]. The monoexponential diffusion coefficients of these tumors, when measured over a normal range of $b$-factors, are moderately elevated (see Table 1). Figures 4A and B display plots of the individual values of the fourteen cases together with concurrently obtained edema and normal white matter values. Considerable variation among the tumor values, may in part be explained by the occasional difficulty to find true tumor tissue and not merely edematous tissue or cystic and necrotic tumor areas. Other mitigating factors, are inferior SNR and low spatial resolution. Also listed in Table 3 are biexponential diffusion parameters of a few low grade (WHO grade I and II) tumor cases. These low grade tumors, if measured over a normal range of $b$-factors, are characterized by strongly elevated monoexponential diffusion coefficients. The fast and slow diffusion coefficients of these low grade tumors are not significantly different from the fast and slow diffusion coefficients of the high grade and metastatic tumors. The only consistently distinguishing diffusion trait of these low grade tumors seems to be a low slow diffusion component size fraction (see Fig. 5). Thus, most likely, the main reason for the variation of the monoexponential diffusion coefficient among different tumors appears to be a change of the component size rather than a change of the diffusion coefficients. This observation, which requires confirmation by a larger number of cases, is quite intriguing in view of a suggested interpretation that the slow diffusion component may be attributed to water next to proteins and close to either side of membrane surfaces and that the fast diffusion component arises from bulk tissue water within both intra- and extracellular compartments [55]. The observed differences in diffusion component size fraction, would then agree with tumor related changes in the quantity of external and internal cell membrane structures and proteins. This hypothesis concurs well with the finding that increases in the slow diffusion component size fraction appears to be associated with more restricted diffusion in the bulk tissue water compartment (see regression line for tumor values in Fig. 4A). Moreover, the hypothesis conveniently also holds in the case of edema, where the fast diffusion component increases in size, whereas the slow diffusion component associated with membrane structures and proteins remains unchanged. Relative increases of both diffusion coefficients, which were observed in more than one study and in different tissues $[7,70,71]$ (see Table 3) can be explained by the swelling-related larger distance between restricting membranes and a rapid exchange between the two compartments. In this context, the negative correlation between slow diffusion component size fraction and fast diffusion coefficient in edema is rather interesting (see Fig. 4A). Edema within the tumor itself, a fact discussed in the previous section, may partially also explain the analogous correlation observed in tumors. Moreover, Valonen et al [41] observed in a rat glioma model during gene therapy-induced programmed cell death, in agreement with the increasing extracellular pool size, a relative increase of the fast diffusion component and both diffusion coefficients. How the model can be applied in the case of acute stroke, where component size fractions show the opposite behavior of edema and diffusion coefficients happen to stay relatively unchanged, remains to be explored [72] (see Table 3). Overall however, this interpretation would have to be reconciled with the observation made in normal brain tissue, that the two distinct diffusion components exhibit such similar $\mathrm{T}_{2}$ values [73], $\mathrm{T}_{1}$ values [74] and magnetization transfer ratios [75].

Also indicated in the plots of Figures 4A and B, for the purpose of reference, is the range of cortical gray matter values that were obtained in a different study with high- $b$ FLAIR diffusion imaging [63]. From the table and the plots it becomes immediately evident, that the fast diffusion component, as the monoexponential diffusion coefficient measured over a 
normal $b$-factor range, permits a good separation between tumor and normal white or gray matter. But also, as in the case of monoexponential analysis, tumor delineation on maps of the fast diffusion coefficient is difficult, because of similarly elevated values in surrounding edema. The slow diffusion component contrast between normal tissue and tumor is marginal, due to the white and gray matter dissociation of the slow diffusion coefficient. Moreover, the separation between tumor and edema is poor, because the respective slow diffusion coefficients are very similar. For the malignant group of tumors the relative diffusion component size, however, appears to provide reasonably good contrast, both between tumor and normal brain tissue, and tumor and edema. Unfortunately, the utility of this contrast for tumor delineation is limited by the poor SNR such maps typically exhibit (see Fig. 2C). Other methods, which characterize the non-monoexponential diffusion-related signal decay with less parameters, such as stretched exponential fitting, as demonstrated for C6 glioma tumors in rats [76] and in human glioma tumor patients [77], or a simplified estimation of excess kurtosis of the diffusion displacement probability distribution [54, 61, 78, 79], may offer superior visualization. Parameter maps generated from patient data with these fitting methods are presented in Figs. 6A and B. The characteristic decay curves shown in Fig. 3 evince, however, that the dissociation of the diffusion related signal decay between tumor and surrounding tissues can be analyzed in other ways. One approach, which has been demonstrated in several studies to be effective for delineating glioblastomas despite surrounding edema, is simply to use images with very high diffusion weighting [7, 80, 81] (see also Figs. 2E and F). Accordingly, far fewer images need to be collected and some of the gain in scan time can be traded for signal averaging. Obviously, this approach implies giving up the clear separation of $\mathrm{T}_{2}$ and diffusion related signal changes and a possible compartment interpretation. Another method for a simplified analysis of the departure from monoexponential diffusion is the computation of the $\chi^{2}$ error of a monoexponential fit. On maps of the $\chi^{2}$ error, glioblastomas (see Fig. 6C) and anaplastic astrocytomas appear much brighter than normal white and gray matter and 2 to 3 times brighter than edematous areas. This observation was also made for human U-87 glioma cell tumors grown in mouse brain (see Fig. 7). On the other hand, the WHO grade I tumors appear to exhibit no change in intensity [82] (see Fig. 8). Unlike the enhancement of $\mathrm{T}_{1^{-}}$ weighted post-contrast images, hyperintensity on $\chi^{2}$ maps was consistently observed within the solid part of the higher grade tumors. In some cases, such as the example shown in Fig. 9 , hyperintensity was also observed outside the tumor boundaries inferred by $\mathrm{T}_{1}$-weighted contrast-enhanced imaging. Although, in some instances this can be attributed to partial volume effects, such hyperintensity seems to indicate malignant cell infiltration [82]. The characteristic hyperintensity of the higher grade tumors on $\chi^{2}$ error maps is in agreement with the observed larger difference between the fast and slow diffusion coefficient in tumor tissue than in normal white and gray matter and a larger slow diffusion fraction in tumor tissue than in edematous tissue or perhaps WHO I grade tumors. The advantage of this and other approaches with a reduced number of parameters, lies not only in the simplified and faster analysis, but also in fewer images that are more easily interpreted and offer superior SNR and contrast.

In summary, high- $b$ diffusion-weighted imaging, although currently purely experimental, seems to provide tumor contrast clearly different from the contrast observed on $\mathrm{T}_{1}$-weighted images. It should be emphasized that diffusion-based tissue differentiation does not depend on the effect of contrast agents, since with the common imaging protocols the diffusionweighted images are only minimally $\mathrm{T}_{1}$-weighted. Biexponential analysis of diffusionweighted images obtained in normal tissues and different pathologies reveals a remarkable range of fast and slow diffusion coefficients and their respective relative size fractions. Careful study of these tissue-dependent parameters may hold the key to the correct identification of the underlying reason for the non-monoexponential diffusion signal decay observed in tissues. Serious limitations for clinical studies are currently the long scan times, 
low SNR and inferior resolution. It is obviously difficult to address any of the particular limitations, without impacting the other limitations. A reduction of sampled $b$-factors is invariably associated with a sacrifice in SNR and a minimum of four $b$-factors must be acquired in order to perform a meaningful biexponential analysis. The high- $b$ image data presented here was acquired with LSDI [14]. For three diffusion encoding directions and 16 $b$-factors the scan time was 6 minutes per slice. Diffusion-weighted imaging with single-shot echo-planar imaging [10] allows for considerably faster acquisition, albeit with more distortions. Scan efficiency can also be improved by changing the acquisition scheme for $b$ factors and directions. For the data presented here, sampling was performed for each $b$ factor along one, three or six directions. This approach allows for relatively straight forward biexponential analysis of the diffusion-weighted data. Wu and Alexander [83] introduced the hybrid diffusion imaging (HYDI) sampling scheme, which acquires less directions at low diffusion weighting, where the directional dependence of the diffusion-encoded signal is minimal. Their clever incorporation of much more diffusion encoding directions at high diffusion weighting requires more demanding post-processing, but improves SNR and adds the capability to detect fiber crossings. Nevertheless, further MR pulse sequence development and the ability to obtain the image data on very high field systems, which afford greater SNR, may be necessary before high- $b$ diffusion imaging and nonmonoexponential signal analysis gains enough appeal for the use in clinical routine imaging.

\section{Tissue Differentiation based on the Directional Dependence of the Diffusion Signal Decay}

Computation of the diffusion tensor yields for each voxel three diffusion coefficients (diffusion eigenvalues) along three orthogonal principal directions (diffusion eigenvectors). In white matter, the eigenvector associated with the largest eigenvalue (principal eigenvector) defines the tissue's fiber tract axis [84]. The directional variability of restricted diffusion is usually quantified by the rotationally invariant fractional anisotropy (FA) index [85], which ranges from 0 (isotropic diffusion) to 1.0 (totally restricted diffusion along two of the three eigenvector directions). Increasingly color coded maps are used for a combined and easy to interpret visualization of anisotropy and principal eigenvector direction [86]. The most useful application of the directional dependence of the diffusion-related signal decay lies not inside the main tumor lesion, but rather within the surrounding highly structured white matter. With maps showing anisotropy and principal eigenvector direction, there are four basic categories of tumor growth related white matter changes that can be observed [87]:

a. Dislocation caused by the mass effect of the tumor and edema is denned by the loss of symmetry, the distorted appearance, and abnormal location of tracts on the anisotropy maps. Principal eigenvectors within the tract remain aligned with the tract orientation. In the absence of edema, the anisotropy within the tract is unchanged.

b. Edema within the fiber structures is characterized by uniformly reduced white matter anisotropy, increased lateral tract dimensions, and absence of localized areas with very low anisotropy. Principal eigenvectors within the tract remain aligned with the tract orientation.

c. Tumor infiltration or invasion is characterized by a variable degree of anisotropy reduction and principal eigenvectors that remain aligned with the tract orientation. Differentiation from edema may be difficult, but localization close to the primary tumor and evidence of high malignancy or the absence of edema on corresponding $\mathrm{T}_{2}$-weighted maps may be indicative of infiltration or invasion. 
d. Complete tract destruction by tumor tissue replacing the original white matter produces a significant loss in anisotropy and lack in coherence of the principal eigenvector directions. The tract destruction may also impress by the abrupt change of anisotropy and eigenvector directions along the tract.

Typically, more than one of these characteristic changes is present and clear differentiation is often not possible. A case with impressive dislocation and swelling of a fiber tract and formation of a large cyst is presented in Fig. 10. Figures 9 and 11 show cases with fiber tract invasion and destruction by a malignant tumor and Fig. 12 illustrates a case with clearly localized tract destruction.

The detection of the course of intact tracts is of fundamental importance to avoid or minimize the injury of displaced but still intact fiber tracts during neurosurgery or radiation therapy $[88,89]$. The ability to obtain such information during surgical procedures, when brain structures are likely to shift position, has also been demonstrated [90-92]. On $\mathrm{T}_{2^{-}}$ weighted images, although gray and white matter exhibit different signal, white matter tract conspicuity is limited and particularly impeded by the presence of edema. The utility of the anisotropy and principal eigenvector information can be extended by following the fiber course over longer distances with diffusion tensor tractography [93]. Thus, a more elaborate analysis of neighbor relations among diffusion tensors opens the possibility for in vivo assessment of axonal fiber connectivity to particular gray matter areas. The combination of these findings with fMRI results allows for non-invasive evaluation of tract function [94,95].

Abnormal anisotropy in a fiber tract, due to edema or the presence of tumor cells, can often be detected by comparison with the anisotropy of the contralateral tract. Moreover, different white matter tracts are well characterized by their different anisotropy values, which can be found in the literature $[96,97]$. The value of anisotropy images to detect tumor infiltration or invasion in white matter has been explored in several studies [98-100], but is very limited due to the confounding effect of edema. Nevertheless, within the peritumoral region showing increased $\mathrm{T}_{2}$-signal, the white matter $\mathrm{FA}$ reduction appears to be greater with high grade gliomas than with other tumors, such as metastases [98] or meningeomas [99]. Most likely, this reflects the particularly invasive nature of high grade gliomas rather than the presence of vasogenic edema only.

Typical tumor tissue exhibits rather low-anisotropic or isotropic diffusion and in general, there is no benefit in analyzing diffusion anisotropy within tumors [101]. As in gray matter, measuring anisotropy in tumors reliably is rather difficult due to the overall low SNR of the commonly used diffusion imaging protocols [97]. Thus minor anisotropy differences, need to be interpreted with caution, since they may very well also be the result of local signal variations and correlated variations in SNR, rather than true differences in cell arrangement. Nevertheless, Goebell et al [102] observed that FA values in the tumor marginal area, but not in the tumor core, differed significantly between low-grade and high-grade gliomas. They concluded that the significant FA difference in the tumor marginal area was the consequence of more extensive fiber tract destruction and accordingly lower anisotropy in high grade gliomas than in low grade gliomas, whereas in the center of the lesions, the fiber destruction was assumed to be more or less complete, irrespective of tumor grade. In contradiction to these findings, Inoue et al [103], who measured FA within the entire tumor body, while carefully excluding large areas of necrosis, observed the lowest anisotropy in grade I and II gliomas (FA=0.150 and 0.159 ) and slightly higher anisotropy in grade III and IV gliomas ( $F A=0.230$ and 0.229$)$. Both studies concur that elevated diffusion anisotropy in tumors may stem from partially destructed white matter tracts. But Inoue moreover attributed the higher anisotropy in high grade gliomas to the typical regular arrangement (like pseudo-palisading) of tumor cells. The latter assumption agrees with findings made by Zhang et al in intracranial tumor bearing rats [104]; in the tumor rim area, FA values were 
elevated between 0.3 and 0.4 and water diffusion directionality formed a circular pattern for 9L and F98 tumors, and a radial pattern for human glioblastoma xenografts. Histological ex vivo analysis confirmed a regular arrangement of tumor cells in agreement with the preferred direction of diffusion.

Most diffusion tensor imaging studies that measure the directional dependence of diffusion employ $b$-factors up to $1,000 \mathrm{~s} / \mathrm{mm}^{2}$. Diffusion imaging at higher $b$-factors increases the dynamic range of directionally dependent signal variations, which can be gainfully applied to detect fibers crossings at high angular resolution. Typically, a prohibitive large number of around 250 directions or more are required to achieve a good level of confidence in measuring fiber orientations within crossings [105]. Scan times easily exceed one hour and volume coverage is limited. Moreover, image post-processing is computationally rather demanding. Therefore, the technique has until now not found widespread use, despite the undisputed value of such measurements for improved fiber tracking. The analysis of nonmonoexponential diffusion over an extended $b$-factor range can also be applied to diffusion tensor imaging studies. Biexponential analysis of diffusion tensor data, with the assumption that size fractions are directionally independent, revealed that the fast and slow diffusion component in normal white matter share the same principal diffusion direction [67]. Thus, apart from an also observed slight difference in anisotropy of the fast and slow diffusion coefficient, biexponential analysis does not provide additional information about the directional dependence of the diffusion process, which would be helpful in the tissue characterization. More advanced $b$-factor and direction sampling scan schemes proposed by Wedeen [106] and $\mathrm{Wu}$ and Alexander [83] permit the concurrent analysis of fiber crossings and non-monoexponential diffusion signal decay.

\section{Conclusion}

Diffusion imaging has become an essential part of MR imaging exams in brain tumor patients. Of immediate value are maps of the mean diffusion coefficient, since they permit the definitive tissue characterization in some cases where $T_{1}$ and $T_{2}$-weighted images alone do not provide enough diagnostic information. Due to the usual presence of edema, which exhibits similar diffusion properties as tumor tissue, demarcation of tumor boundaries on diffusion maps is often not practical. Moreover, delineation and the visibility of small features is impeded by a spatial resolution clearly inferior to the spatial resolution of standard $\mathrm{T}_{1}$ and $\mathrm{T}_{2}$-weighted images. Other diagnostic applications of diffusion imaging are not possible in every case, since they may require the acquisition of much larger image data sets, advanced image processing, or repeat scans. Nevertheless, diffusion-based fiber tract localization has been embraced by the clinical community and is now often performed during treatment planning. For reliable and most rapid volume coverage, diffusion images to be used for fiber tract localization are typically obtained with the single-shot echo-planar method. The inherent geometric distortions of images obtained with this method require careful consideration when the spatial tract information is used within another reference space, e.g., during surgery. Diffusion-based documentation of cellular response during drug or radiation therapy is likely to become an integral part of clinical treatment monitoring. The application of diffusion imaging with an extended $b$-factor range shows some interesting potential for diagnostic imaging in brain tumors and improved detection of crossing nerve fiber tracts. Further research is needed to explore the clinical value of these approaches. For clinical routine use, analysis methods that facilitate simple and reliable clinical evaluation, rather than correct physical interpretation, may be necessary. Above all, however, further technical development is required to reduce the excessive scan times and limitations in spatial resolution. Advances on this front, may also be beneficial to basic diffusion imaging. 


\section{Acknowledgments}

Part of the research presented in this review was supported by a research grant from the National Institute of Biomedical Imaging (R01 EB006867 to S.E.M.) and a resource grant funded jointly by the National Center for Research Resources, the National Cancer Institute, and the National Institute of Biomedical Imaging (U41 RR019703).

\section{References}

1. Tsuruda JS, Chew WM, Moseley ME, Norman D. Diffusion-weighted MR imaging of the brain: Value of differentiating between extraaxial cysts and epidermoid tumors. Am J Neuroradiol. 1990; 11(5):925-931. [PubMed: 2120997]

2. Essig M, Hawighorst H, Schoenberg SO, Engenhart-Cabillic R, Fuss M, Debus J, Zuna I, Knopp MV, van Kaick G. Fast fluid-attenuated inversion-recovery (FLAIR) MRI in the assessment of intraaxial brain tumors. J Magn Reson Imaging. 1998; 8(4):789-798. [PubMed: 9702879]

3. Cha S. Perfusion MR imaging of brain tumors. Top Magn Reson Imaging. 2004; 15(5):279-289. Review. [PubMed: 15627003]

4. Roberts HC, Roberts TP, Brasch RC, Dillon WP. Quantitative measurement of microvascular permeability in human brain tumors achieved using dynamic contrast-enhanced mr imaging: correlation with histologic grade. Am J Neuroradiol. 2000; 21(5):891-899. [PubMed: 10815665]

5. Sehgal V, Delproposto Z, Haddar D, Haacke EM, Sloan AE, Zamorano LJ, Barger G, Hu J, Xu Y, Prabhakaran KP, Elangovan IR, Neelavalli J, Reichenbach JR. Susceptibility-weighted imaging to visualize blood products and improve tumor contrast in the study of brain masses. J Magn Reson Imaging. 2006; 24(1):41-51. [PubMed: 16755540]

6. Preul MC, Caramanos Z, Leblanc R, Villemure JG, Arnold DL. Using pattern analysis of in vivo proton MRSI data to improve the diagnosis and surgical management of patients with brain tumors. NMR Biomed. 1997; 87(1):113-121.

7. Maier SE, Bogner P, Bajzik G, Mamata H, Mamata Y, Repa I, Jolesz FA, Mulkern RV. Normal brain and brain tumor: Multicomponent apparent diffusion coefficient line scan imaging. Radiology. 2001; 219:842-849. [PubMed: 11376280]

8. Okumura A, Takenaka K, Nishimura Y, Asano Y, Sakai N, Kuwata K, Era S. The characterization of human brain tumor using magnetization transfer technique in magnetic resonance imaging. Neurol Res. 1999; 21(3):250-254. [PubMed: 10319332]

9. Zhou J, Blakeley JO, Hua J, Kim M, Laterra J, Pomper MG, van Zijl PC. Practical data acquisition method for human brain tumor amide proton transfer (APT) imaging. Magn Reson Med. 2008; 60(4):842-849. [PubMed: 18816868]

10. Turner R, Le Bihan D, Maier J, Vavrek R, Hedges LK, Pekar J. Echo-planar imaging of intravoxel incoherent motions. Radiology. 1990; 177:407-414. [PubMed: 2217777]

11. Jaermann T, Crelier G, Pruessmann K, Golay X, Netsch T, van Muiswinkel AM, Mori S, van Zijl P, Valavanis A, Kollias S, Boesiger P. SENSE-DTI at 3 T. Magn Reson Med. 2004; 51(2):230236. [PubMed: 14755645]

12. Pipe JG, Farthing VG, Forbes KP. Multishot diffusion-weighted FSE using PROPELLER MRI. Magn Reson Med. 2002; 47(1):42-52. [PubMed: 11754441]

13. Holdsworth SJ, Skare S, Newbould RD, Bammer R. Robust GRAPPA-accelerated diffusionweighted readout-segmented (RS)-EPI. Magn Reson Med. 2009; 62(6):1629-1640. [PubMed: 19859974]

14. Gudbjartsson H, Maier SE, Mulkern RV, Mórocz IÁ, Patz S, Jolesz FA. Line scan diffusion imaging. Magn Reson Med. 1996; 36(4):509-519. [PubMed: 8892201]

15. Chenevert TL, Pipe JG, Williams DM, Brunberg JA. Quantitative measurement of tissue perfusion and diffusion in vivo. Magn Reson Med. 1991; 17:197-212. [PubMed: 2067394]

16. van Rijswijk CS, Kunz P, Hogendoorn PC, Taminiau AH, Doornbos J, Bloem JL. Diffusionweighted MRI in the characterization of soft-tissue tumors. J Magn Reson Imaging. 2002; 15:302307. [PubMed: 11891975] 
17. Morita K, Matsuzawa H, Fujii Y, Tanaka R, Kwee IL, Nakada T. Diffusion tensor analysis of peritumoral edema using lambda chart analysis indicative of the heterogeneity of the microstructure within edema. J Neurosurg. 2005; 102(2):336-341. [PubMed: 15739563]

18. Yamasaki F, Kurisu K, Satoh K, Arita K, Sugiyama K, Ohtaki M, Takaba J, Tominaga A, Hanaya R, Yoshioka H, Hama S, Ito Y, Kajiwara Y, Yahara K, Saito T, Thohar MA. Apparent diffusion coefficient of human brain tumors at MR imaging. Radiology. 2005; 235(3):985-991. [PubMed: 15833979]

19. Pronin IN, Kornienko VN, Fadeeva LM, Rodionov PV, Golanov AV. Diffusion-weighted image in the study of brain tumors and peritumoral edema (article in Russian). Zh Vopr Neirokhir Im N N Burdenko. 2000 Jul-Sep.(3):14-16. [PubMed: 11221335]

20. Guo AC, Cummings TJ, Dash RC, Provenzale JM. Lymphomas and high-grade astrocytomas: comparison of water diffusibility and histologic characteristics. Radiology. 2002; 224(1):177-183. [PubMed: 12091680]

21. Kono K, Inoue Y, Nakayama K, Shakudo M, Morino M, Ohata K, Wakasa K, Yamada R. The role of diffusion-weighted imaging in patients with brain tumors. Am J Neuroradiol. 2001; 22(6):10811088. [PubMed: 11415902]

22. Dorenbeck U, Grunwald IQ, Schlaier J, Feuerbach S. Diffusion-weighted imaging with calculated apparent diffusion coefficient of enhancing extra-axial masses. J Neuroimaging. 2005; 15(4):314317.

23. Rumboldt Z, Camacho DL, Lake D, Welsh CT, Castillo M. Apparent diffusion coefficients for differentiation of cerebellar tumors in children. Am J Neuroradiol. 2006; 27(6):1362-1369. [PubMed: 16775298]

24. Tozer DJ, Jäger HR, Danchaivijitr N, Benton CE, Tofts PS, Rees JH, Waldman AD. Apparent diffusion coefficient histograms may predict low-grade glioma subtype. NMR Biomed. 2007; 20(1):49-57. [PubMed: 16986106]

25. Mishra AM, Gupta RK, Saksena S, Prasad KN, Pandey CM, Rathore D, Purwar A, Rathore RK, Husain N, Jha DK, Jaggi RS. M H. Biological correlates of diffusivity in brain abscess. Magn Reson Med. 2005; 54(4):663-667.

26. Uhl M, Altehoefer C, Kontny U, Il'yasov K, Buchert M, Langer M. MRI-diffusion imaging of neuroblastomas: First results and correlation to histology. Eur Radiol. 2002; 12(9):2335-2338. [PubMed: 12195491]

27. Rodallec M, Colombat M, Krainik A, Kalamarides M, Redondo A, Feydy A. Diffusion-weighted MR imaging and pathologic findings in adult cerebellar medulloblastoma. J Neuroradiol. 2004; 31(3):234-237. [PubMed: 15356452]

28. Sugahara T, Korogi Y, Kochi M, Ikushima I, Shigematu Y, Hirai T, Okuda T, Liang L, Ge Y, Komohara Y, Ushio Y, Takahashi M. Usefulness of diffusion-weighted MRI with echo-planar technique in the evaluation of cellularity in gliomas. J Magn Reson Imaging. 1999; 9(1):53-60. [PubMed: 10030650]

29. Gupta RK, Cloughesy TF, Sinha U, Garakian J, Lazareff J, Rubino G, Rubino L, Becker DP, Vinters HV, Alger JR. Relationships between choline magnetic resonance spectroscopy, apparent diffusion coefficient and quantitative histopathology in human glioma. J Neurooncol. 2000; 50(3): 215-226. [PubMed: 11263501]

30. Gauvain KM, McKinstry RC, Mukherjee P, Perry A, Neil JJ, Kaufman BA, Hayashi RJ. Evaluating pediatric brain tumor cellularity with diffusion-tensor imaging. Am J Roentgenol. 2001; 177(2):449-454. [PubMed: 11461881]

31. Lyng H, Haraldseth O, Rofstad E. Measurement of cell density and necrotic fraction in human melanoma xenografts by diffusion weighted magnetic resonance imaging. Magn Reson Med. 2000; 43(6):828-836. [PubMed: 10861877]

32. Takahashi M, Hackney D, Zhang G, Wehrli S, Wright A, O’Brien W, Uematsu H, Wehrli F, Selzer M. Magnetic resonance microimaging of intraaxonal water diffusion in live excised lamprey spinal cord. Proc Natl Acad Sci USA. 2002; 99(25):16192-16196. [PubMed: 12451179]

33. Steen RG. Edema and tumor perfusion: characterization by quantitative $1 \mathrm{H}$ MR imaging. Am J Roentgenol. 1992; 158(2):259-264. [PubMed: 1729777] 
34. Maeda M, Kawamura Y, Tamagawa Y, Matsuda T, Itoh S, Kimura H, Iwasaki T, Hayashi N, Yamamoto K, Ishii Y. Intravoxel incoherent motion (IVIM) MRI in intracranial, extraaxial tumors and cysts. J Comput Assist Tomogr. 1992; 16(4):514-518. [PubMed: 1629406]

35. Chen S, Ikawa F, Kurisu K, Arita K, Takaba J, Kanou Y. Quantitative MR evaluation of intracranial epidermoid tumors by fast fluid-attenuated inversion recovery imaging and echoplanar diffusion-weighted imaging. Am J Neuroradiol. 2001; 22(6):1089-1096. [PubMed: 11415903]

36. Ebisu T, Tanaka C, Umeda M, Kitamura M, Naruse S, Higuchi T, Ueda S, Sato H. Discrimination of brain abscess from necrotic or cystic tumors by diffusion-weighted echo planar imaging. Magn Reson Imaging. 1996; 14(9):1113-1116. [PubMed: 9071004]

37. Noguchi K, Watanabe N, Nagayoshi T, Kanazawa T, Toyoshima S, Shimizu M, Seto H. Role of diffusion-weighted echo-planar MRI in distinguishing between brain abscess and tumour: A preliminary report. Neuroradiology. 1999; 41(3):171-174. [PubMed: 10206159]

38. Chang SC, Lai PH, Chen WL, Weng HH, Ho JT, Wang JS, Chang CY, Pan HB, Yang CF. Diffusion-weighted MRI features of brain abscess and cystic or necrotic brain tumors: Comparison with conventional MRI. Clin Imaging. 2002; 26(4):227-236. [PubMed: 12140151]

39. Mardor Y, Roth Y, Lidar Z, Jonas T, Pfeffer R, Maier SE, Faibel M, Nass D, Hadani M, Orenstein A, Cohen JS, Ram Z. Monitoring response to convection-enhanced Taxol delivery in brain tumor patients using diffusion-weighted magnetic resonance imaging. Cancer Res. 2001; 61(13):49714973. [PubMed: 11431326]

40. Mardor Y, Pfeffer R, Spiegelmann R, Roth Y, Maier SE, Nissim O, Berger R, Glicksman A, Baram J, Orenstein A, Cohen JS, Tichler T. Early detection of response to radiation therapy in patients with brain malignancies using conventional and high b-value diffusion weighted MRI. J Clin Oncol. 2003; 21(6):1094-1100. [PubMed: 12637476]

41. Valonen PK, Lehtimäki KK, Väisänen TH, Kettunen MI, Gröhn OH, Ylä-Herttuala S, Kauppinen RA. Water diffusion in a rat glioma during ganciclovir-thymidine kinase gene therapy-induced programmed cell death in vivo: correlation with cell density. J Magn Reson Imaging. 2004; 19(4): 389-396. [PubMed: 15065161]

42. Chan YL, Yeung DK, Leung SF, Chan PN. Diffusion-weighted magnetic resonance imaging in radiation-induced cerebral necrosis. apparent diffusion coefficient in lesion components. J Comput Assist Tomogr. 2003; 27(5):674-680. [PubMed: 14501357]

43. Chenevert TL, Meyer CR, Moffat BA, Rehemtulla A, Mukherji SK, Gebarski SS, Quint DJ, Robertson PL, Lawrence TS, Junck L, Taylor JM, Johnson TD, Dong Q, Muraszko KM, Brunberg JA, Ross BD. Diffusion MRI: a new strategy for assessment of cancer therapeutic efficacy. Mol Imaging. 2002; 1(4):336-343. [PubMed: 12926229]

44. Mardor Y, Roth Y, Ochershvilli A, Spiegelmann R, Tichler T, Daniels D, Maier SE, Nissim O, Ram Z, Baram J, Orenstein A, Pfeffer R. Pre-treatment prediction of brain tumors response to radiation therapy using high b-value diffusion-weighted MRI. Neoplasia. 2004; 6(2):136-142. [PubMed: 15140402]

45. Moffat BA, Chenevert TL, Lawrence TS, Meyer CR, Johnson TD, Dong Q, Tsien C, Mukherji S, Quint DJ, Gebarski SS, Robertson PL, Junck LR, Rehemtulla A, Ross BD. Functional diffusion map: A noninvasive MRI biomarker for early stratification of clinical brain tumor response. Proc Natl Acad Sci USA. 2005; 102(15):5524-5529. [PubMed: 15805192]

46. Huang CF, Chou HH, Tu HT, Yang MS, Lee JK, Lin LY. Diffusion magnetic resonance imaging as an evaluation of the response of brain metastases treated by stereotactic radiosurgery. Surg Neurol. 2008; 69(1):62-68. [PubMed: 18054618]

47. Assaf Y, Cohen Y. Non-mono-exponential attenuation of water and $\mathrm{N}$-acetyl aspartate signals due to diffusion in brain tissue. J Magn Reson. 1998; 131(1):69-85. [PubMed: 9533908]

48. Mulkern RV, Gudbjartsson H, Westin CF, Zengingonul HP, Gartner W, Guttmann CR, Robertson R, Kyriakos W, Schwartz R, Holtzman D, Jolesz FA, Maier SE. Multi-component apparent diffusion coefficients in human brain. NMR in Biomedicine. 1999; 12:51-62. [PubMed: 10195330]

49. Gudbjartsson H, Patz S. The Rician distribution of noisy MRI data. Magn Reson Med. 1995; 34(6): 910-914. [PubMed: 8598820] 
50. Jones DK, Basser PJ. "Squashing peanuts and smashing pumpkins": how noise distorts diffusionweighted MR data. Magn Reson Med. 2004; 52(5):979-993. [PubMed: 15508154]

51. Maier SE, Hardy CJ, Jolesz FA. Real-time quantification of brain and CSF motion with M-mode MR. Radiology. 1994; 193:477-483. [PubMed: 7972766]

52. Bennett KM, Schmainda K, Bennett R, Rowe D, Lu H, Hyde J. Characterization of continuously distributed cortical water diffusion rates with a stretched-exponential model. Magn Reson Med. 2003; 50(4):727-734. [PubMed: 14523958]

53. Yablonskiy DA, Bretthorst GL, Ackerman JJ. Statistical model for diffusion attenuated MR signal. Magn Reson Med. 2003; 50(4):664-669. [PubMed: 14523949]

54. Kiselev VG, Il'yasov KA. Is the "biexponential diffusion” biexponential? Magn Reson Med. 2007; 57(3):464-469. [PubMed: 17326171]

55. Le Bihan D. The "wet mind": Water and functional neuroimaging. Phys Med Biol. 2007; 52(7):R57-R90. [PubMed: 17374909]

56. Zhou XJ, Gao Q, Abdullah O, Magin RL. Studies of anomalous diffusion in the human brain using fractional order calculus. Magn Reson Med. 2010; 63(3):562-569. [PubMed: 20187164]

57. Lee JH, Springer CSJ. Effects of equilibrium exchange on diffusion-weighted NMR signals: the diffusigraphic "shutter-speed". Magn Reson Med. 2003; 49(3):450-458. [PubMed: 12594747]

58. Harkins KD, Galons JP, Secomb TW, Trouard TP. Assessment of the effects of cellular tissue properties on ADC measurements by numerical simulation of water diffusion. Magn Reson Med. 2009; 62(6):1414-1422. [PubMed: 19785014]

59. Vestergaard-Poulsen P, Hansen B, Østergaard L, Jakobsen R. Microstructural changes in ischemic cortical gray matter predicted by a model of diffusion-weighted MRI. J Magn Reson Imaging. 2007; 26(3):529-540. [PubMed: 17685422]

60. Jespersen SN, Kroenke CD, Ostergaard L, Ackerman JJ, Yablonskiy DA. Modeling dendrite density from magnetic resonance diffusion measurements. NeuroImage. 2007; 34(4):1473-1486. [PubMed: 17188901]

61. Jensen JH, Helpern JA, Ramani A, Lu H, Kaczynski K. Diffusional kurtosis imaging: the quantification of non-gaussian water diffusion by means of magnetic resonance imaging. Magn Reson Med. 2005; 53(6):1432-1440. [PubMed: 15906300]

62. Acton, FS. Numerical methods that work. 2 edition. Washington, DC: The Mathematical Association of America; 1990.

63. Maier SE, Mulkern RV. Biexponential analysis of diffusion related signal decay in normal human cortical and deep gray matter. Magn Reson Imaging. 2008; 26(7):897-904. [PubMed: 18467062]

64. Mulkern RV, Haker SJ, Maier SE. On high b diffusion imaging in the human brain: Ruminations and experimental insights. Magn Reson Imaging. 2009; 27(8):1151-1162. [PubMed: 19520535]

65. Mulkern RV, Vajapeyam S, Robertson RL, Caruso PA, Rivkin MJ, Maier SE. Biexponential apparent diffusion coefficient parametrization in adult vs newborn brain. Magn Reson Imaging. 2001; 19(5):659-668. [PubMed: 11672624]

66. Clark CA, Hedehus M, Moseley ME. In vivo mapping of the fast and slow diffusion tensors in human brain. Magn Reson Med. 2002; 47(4):623-628. [PubMed: 11948721]

67. Maier SE, Vajapeyam S, Mamata H, Westin CF, Jolesz FA, Mulkern RV. Biexponential diffusion tensor analysis of human brain diffusion data. Magn Reson Med. 2004; 51(2):321-330. [PubMed: 14755658]

68. DeLano MC, Cooper TG, Siebert JE, Potchen MJ, Kuppusamy K. High-b-value diffusionweighted MR imaging of adult brain: image contrast and apparent diffusion coefficient map features. Am J Neuroradiol. 2000; 21(10):1830-1836. [PubMed: 11110534]

69. Yoshiura T, Wu O, Zaheer A, Reese TG, Sorensen AG. Highly diffusion-sensitized MRI of brain: dissociation of gray and white matter. Magn Reson Med. 2001; 45(5):734-740. [PubMed: 11323798]

70. Schwarcz A, Ursprung Z, Berente Z, Bogner P, Kotek G, Meric P, Gillet B, Beloeil JC, Dczi T. In vivo brain edema classification: New insight offered by large $b$-value diffusion-weighted MR imaging. J Magn Reson Imaging. 2007; 25(1):26-31. [PubMed: 17173312]

71. Ababneh Z, Beloeil H, Berde CB, Gambarota G, Maier SE, Mulkern RV. Biexponential parametrization of diffusion and $\mathrm{T} 2$ relaxation decay curves in a rat muscle edema model: Decay 
curve components and water compartments. Magn Reson Med. 2005; 54(3):524-531. [PubMed: 16086363]

72. Brugieres P, Thomas P, Maraval A, Hosseini H, Combes C, Chafiq A, Ruel L, Breil S, Peschanski $\mathrm{M}$, Gaston A. Water diffusion compartmentation at high b values in ischemic human brain. Am J Neuroradiol. 2004; 25(5):692-698. [PubMed: 15140706]

73. Clark CA, Le Bihan D. Water diffusion compartmentation and anisotropy at high $b$ values in the human brain. Magn Reson Med. 2000; 44(6):852-859. [PubMed: 11108621]

74. Mulkern RV, Zengingonul HP, Robertson RL, Bogner P, Gudbjartsson H, Guttmann CR, Holtzman D, Kyriakos W, Jolesz FA, Maier SE. Multi-component apparent diffusion coefficients in human brain: Relationship to spin-lattice relaxation. Magn Reson Med. 2000; 44:292-300. [PubMed: 10918329]

75. Mulkern RV, Vajapeyam S, Haker SJ, Maier SE. Magnetization transfer studies of the fast and slow tissue water diffusion components in the human brain. NMR in Biomedicine. 2005; 18(3): 186-194. [PubMed: 15578729]

76. Bennett KM, Hyde JS, Rand S, Bennett R, Krouwer HG, Rebro KJ, Schmainda KM. Intravoxel distribution of DWI decay rates reveals C6 glioma invasion in rat brain. Magn Reson Med. 2004; 52(5):994-1004. [PubMed: 15508160]

77. Raab P, Hattingen E, Franz K, Zanella F, Lanfermann H. Cerebral gliomas: diffusional kurtosis imaging analysis of microstructural differences. Radiology. 2010; 254(3):876-881. [PubMed: 20089718]

78. Peled S, Whalen S, Jolesz FA, Golby AJ. High b-value apparent diffusion-weighted images from CURVE-ball DTI. J Magn Reson Imaging. 2009; 30(1):243-248. [PubMed: 19557743]

79. Kwee TC, Galbn CJ, Tsien C, Junck L, Sundgren PC, Ivancevic MK, Johnson TD, Meyer CR, Rehemtulla A, Ross BD, Chenevert TL. Intravoxel water diffusion heterogeneity imaging of human high-grade gliomas. NMR Biomed. 2010; 23(2):179-187. [PubMed: 19777501]

80. Alvarez-Linera J, Benito-Len J, Escribano J, Rey G. Predicting the histopathological grade of cerebral gliomas using high b value MR DW imaging at 3-tesla. J Neuroimaging. 2008; 18(3): 276-281. [PubMed: 18482368]

81. Seo HS, Chang KH, Na DG, Kwon BJ, Lee DH. High b-value diffusion $\left(b=3000 \mathrm{~s} / \mathrm{mm}^{2}\right)$ MR imaging in cerebral gliomas at 3T: visual and quantitative comparisons with $b=1000 \mathrm{~s} / \mathrm{mm}^{2}$. Am J Neuroradiol. 2008; 29(3):458-463. [PubMed: 18065512]

82. Maier SE, Mamata H, Mulkern RV. Characterization of normal brain and brain tumor pathology by chisquares parameter maps of diffusion-weighted image data. Eur J Radiol. 2003; 45(3):199_ 207. [PubMed: 12595104]

83. Wu YC, Alexander AL. Hybrid diffusion imaging. NeuroImage. 2007; 36(3):617-629. [PubMed: 17481920]

84. Lin CP, Tseng WY, Cheng HC, Chen JH. Validation of diffusion tensor magnetic resonance axonal fiber imaging with registered manganese-enhanced optic tracts. Neuroimage. $2001 ; 14(5)$ : 1035-1047. [PubMed: 11697935]

85. Papadakis NG, Xing D, Houston GC, Smith JM, Smith MI, James MF, Parsons AA, Huang CL, Hall LD, Carpenter TA. A study of rotationally invariant and symmetric indices of diffusion anisotropy. Magn Reson Imaging. 1999; 17(6):881-892. [PubMed: 10402595]

86. Pajevic S, Pierpaoli C. Color schemes to represent the orientation of anisotropic tissues from diffusion tensor data: application to white matter fiber tract mapping in the human brain. Magn Reson Med. 1999; 42(3):526-540. [PubMed: 10467297]

87. Field AS, Alexander AL, Wu YC, Hasan KM, Witwer B, Badie B. Diffusion tensor eigenvector directional color imaging patterns in the evaluation of cerebral white matter tracts altered by tumor. J Magn Reson Imaging. 2004; 20(4):555-562. [PubMed: 15390227]

88. Holodny AI, Schwartz TH, Ollenschleger M, Liu WC, Schulder M. Tumor involvement of the corticospinal tract: Diffusion magnetic resonance tractography with intraoperative correlation. $\mathrm{J}$ Neurosurg. 2001; 95(6):1082. [PubMed: 11765829]

89. Yu CS, Li KC, Xuan Y, Ji XM, Qin W. Diffusion tensor tractography in patients with cerebral tumors: a helpful technique for neurosurgical planning and postoperative assessment. Eur J Radiol. 2005; 56(2):197-204. [PubMed: 15916876] 
90. Nimsky C, Ganslandt O, Hastreiter P, Wang R, Benner T, Sorensen AG, Fahlbusch R. Intraoperative diffusion-tensor MR imaging: shifting of white matter tracts during neurosurgical procedures - initial experience. Radiology. 2005; 234(1):218-225. [PubMed: 15564394]

91. Nimsky C, Ganslandt O, Hastreiter P, Wang R, Benner T, Sorensen AG, Fahlbusch R. Preoperative and intraoperative diffusion tensor imaging-based fiber tracking in glioma surgery. Neurosurgery. 2005; 56(1):130-137. [PubMed: 15617595]

92. Maesawa S, Fujii M, Nakahara N, Watanabe T, Saito K, Kajita Y, Nagatani T, Wakabayashi T, Yoshida J. Clinical indications for high-field 1.5 T intraoperative magnetic resonance imaging and neuronavigation for neurosurgical procedures. review of initial 100 cases. Neurol Med Chir (Tokyo). 2009; 49(8):340-349. [PubMed: 19706999]

93. Basser PJ, Pajevic S, Pierpaoli C, Duda J, Aldroubi A. In vivo fiber tractography using DT-MRI data. Magn Reson Med. 2000; 44(4):625-632. [PubMed: 11025519]

94. Ulmer JL, Salvan CV, Mueller WM, Krouwer HG, Stroe GO, Aralasmak A, Prost RW. The role of diffusion tensor imaging in establishing the proximity of tumor borders to functional brain systems: implications for preoperative risk assessments and postoperative outcomes. Technol Cancer Res Treat. 2004; 3(6):567-576. [PubMed: 15560714]

95. Rosiene J, Liu X, Imielinska C, Ferrera J, Bruce J, Hirsch J, D’Ambrosio A. Structure-function relationships in the human visual system using DTI, fMRI and visual field testing: pre- and postoperative assessments in patients with anterior visual pathway compression. Stud Health Technol Inform. 2006; 119:464-466. [PubMed: 16404100]

96. Pierpaoli C, Jezzard P, Basser P, Barnett A, Di Chiro G. Diffusion tensor MR imaging of the human brain. Radiology. 1996; 201(3):637-648. [PubMed: 8939209]

97. Mamata H, Jolesz FA, Maier SE. Characterization of central nervous system structures by magnetic resonance diffusion anisotropy. Neurochem Int. 2004; 45(4):553-560. [PubMed: 15186922]

98. Price S, Burnet N, Donovan T, Green H, Pena A, Antoun N, Pickard J, Carpenter T, Gillard J. Diffusion tensor imaging of brain tumours at 3T: a potential tool for assessing white matter tract invasion? Clin Radiol. 2003; 58(6):455-462. [PubMed: 12788314]

99. Provenzale JM, McGraw P, Mhatre P, Guo AC, Delong D. Peritumoral brain regions in gliomas and meningiomas: Investigation with isotropic diffusion-weighted MR imaging and diffusiontensor MR imaging. Radiology. 2004; 232(2):451-460. [PubMed: 15215555]

100. Tropine A, Vucurevic G, Delani P, Boor S, Hopf N, Bohl J, Stoeter P. Contribution of diffusion tensor imaging to delineation of gliomas and glioblastomas. J Magn Reson Imaging. 2004; 20(6): 905-912. [PubMed: 15558549]

101. Sinha S, Bastin ME, Whittle IR, Wardlaw JM. Diffusion tensor MR imaging of high-grade cerebral gliomas. Am J Neuroradiol. 2002; 23(4):520-527. [PubMed: 11950638]

102. Goebell E, Paustenbach S, Vaeterlein O, Ding XQ, Heese O, Fiehler J, Kucinski T, Hagel C, Westphal M, Zeumer H. Low-grade and anaplastic gliomas: Differences in architecture evaluated with diffusion-tensor MR imaging. Radiology. 2006; 239(1):217-222. [PubMed: 16484348]

103. Inoue T, Ogasawara K, Beppu T, Ogawa A, Kabasawa H. Diffusion tensor imaging for preoperative evaluation of tumor grade in gliomas. Clin Neurol Neurosurg. 2005; 107(3):174180. [PubMed: 15823671]

104. Zhang J, van Zijl PC, Laterra J, Salhotra A, Lal B, Mori S, Zhou J. Unique patterns of diffusion directionality in rat brain tumors revealed by high-resolution diffusion tensor MRI. Magn Reson Med. 2007; 58(3):454-462. [PubMed: 17763344]

105. Tuch DS. Q-ball imaging. Magn Reson Med. 2004; 52(6):1358-1372. [PubMed: 15562495]

106. Wedeen VJ, Hagmann P, Tseng WY, Reese TG, Weisskoff RM. Mapping complex tissue architecture with diffusion spectrum magnetic resonance imaging. Magn Reson Med. 2005; 54(6):1377-1386. [PubMed: 16247738]

107. Maier SE, Gudbjartsson H, Patz S, Hsu L, Lovblad KO, Edelman RR, Warach S, Jolesz FA. Line scan diffusion imaging: Characterization in healthy subjects and stroke patients. Am J Roentgen. 1998; 17(1):85-93. 
108. Helenius J, Soinne L, Perkio J, Salonen O, Kangasmaki A, Kaste M, Carano RA, Aronen HJ, Tatlisumak T. Diffusion-weighted MR imaging in normal human brains in various age groups. Am J Neuroradiol. 2002; 23(2):194-199. [PubMed: 11847041]

109. Hakyemez B, Yildirim N, Gokalp G, Erdogan C, Parlak M. The contribution of diffusionweighted MR imaging to distinguishing typical from atypical meningiomas. Neuroradiology. 2006; 48(8):512-520.

110. Marks MP, de Crespigny A, Lentz D, Enzmann DR, Alberts GW, Moseley ME. Acute and chronic stroke: Navigated spin-echo diffusion-weighted MR imaging. Radiology. 1996; 199:403-408. [PubMed: 8668785]

\section{List of Symbols}

G Magnetic Field Gradient Amplitude

$\boldsymbol{\delta}$ Gradient Duration

$\Delta \quad$ Gadient Separation

b Diffusion Weighting

$\gamma \quad$ Gyromagnetic Ratio

$S \quad$ Signal

$S_{0} \quad$ Signal without Diffusion Weighting

D Diffusion Coefficient

$\boldsymbol{D}_{\boldsymbol{f}} \quad$ Fast Diffusion Coefficient

$D_{s} \quad$ Slow Diffusion Coefficient

$\boldsymbol{A}_{\boldsymbol{f}} \quad$ Fast Diffusion Coefficient Amplitude

$\boldsymbol{A}_{\boldsymbol{s}} \quad$ Slow Diffusion Coefficient Amplitude

$f_{f} \quad$ Relative Size Fraction of Fast Diffusion Coefficient

$f_{s} \quad$ Relative Size Fraction of Slow Diffusion Coefficient

ADC Apparent Diffusion Coefficient

$\boldsymbol{T}_{\mathbf{1}} \quad$ Spin-Lattice Relaxation Time

$\boldsymbol{T}_{\mathbf{2}} \quad$ Spin-Spin Relaxation Time

Ф Phase Shift

v Velocity

a Stretched Exponential Parameter Alpha

K Kurtosis Parameter

$\chi^{2} \quad$ Error Measure of Data Fit

FA Fractional Anisotropy 

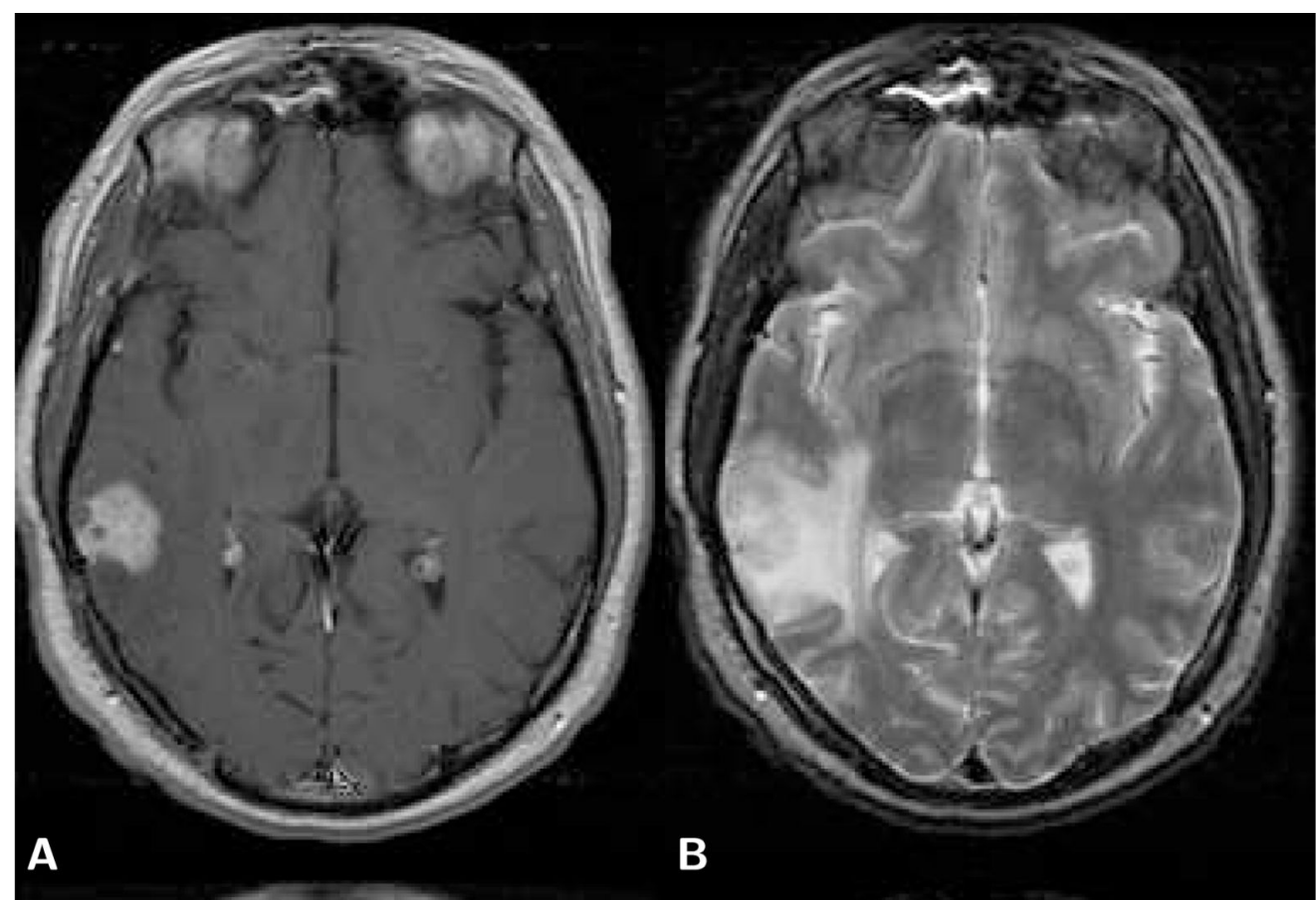

B

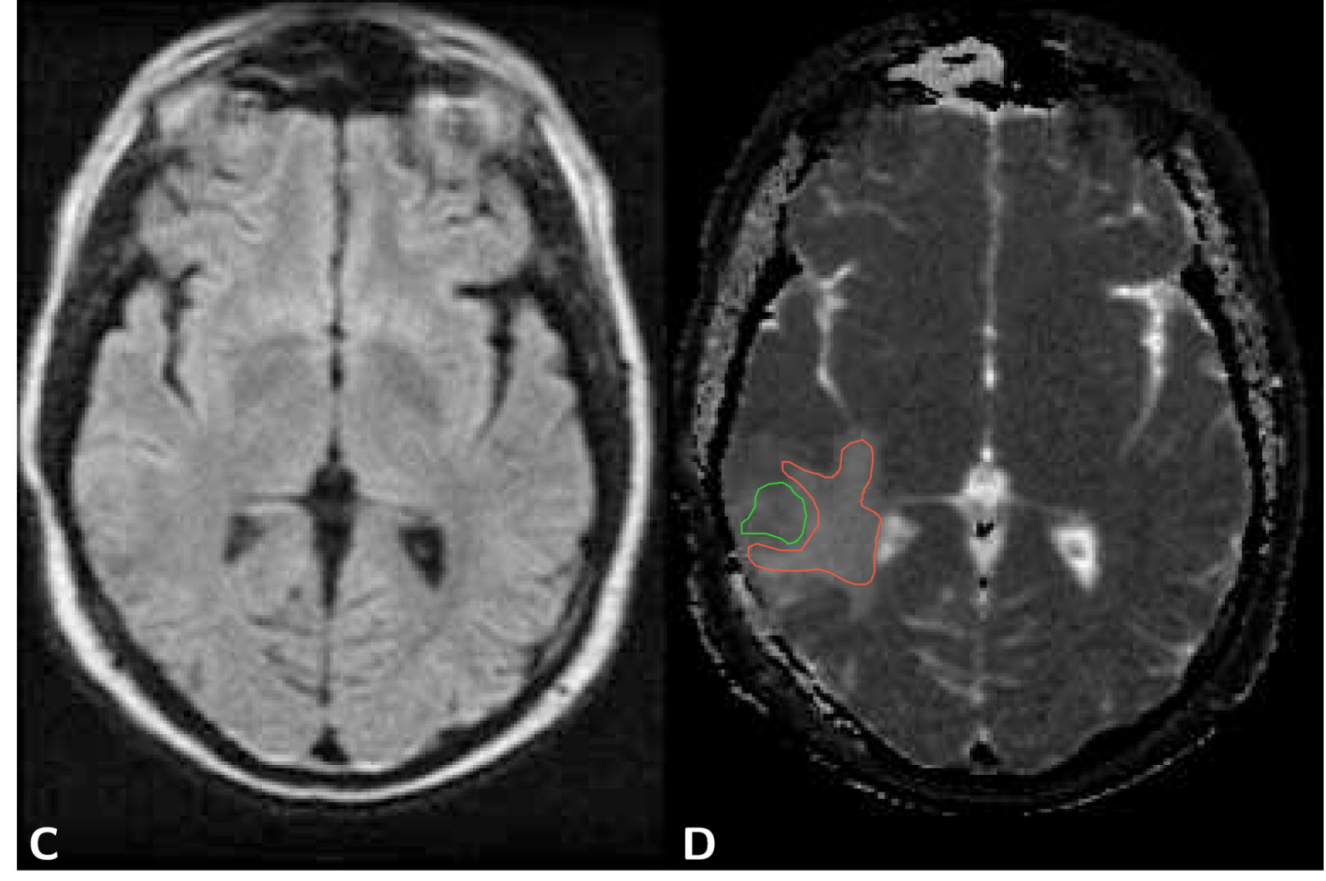

Figure 1.

Axial brain images of a 40 year old female patient with a glioblastoma. A) $\mathrm{T}_{1}$-weighted post-contrast spin-echo image (TR $600 \mathrm{~ms} / \mathrm{TE} 14 \mathrm{~ms}$ ) shows an enhancing lesion. B) $\mathrm{T}_{2}$ weighted spin-echo image (TR 3,000 ms/TE $92 \mathrm{~ms}$ ) shows the lesion and larger area with edema. C) The same area on the LSDI mean diffusion-weighted image ( $b$-factor 1,000 s/ $\mathrm{mm}^{2}$ ) appears isointense with the surrounding normal tissue. There is evidence, however, of slight deformation of the ventricle and sulcus anatomy. D) Mean diffusion coefficient map exhibits elevated diffusion both within lesion and edema. ADC measured within the green region of interest (ROI) outline for tumor (defined on the $\mathrm{T}_{1}$-weighted image) is $1.18 \mu \mathrm{m}^{2}$ / 
ms and within the red ROI outline for edema $1.35 \mu \mathrm{m}^{2} / \mathrm{ms}$. Gray and white matter show no obvious difference in diffusion and appear dark gray ( $\left.\mathrm{ADC}=0.76 \mu \mathrm{m}^{2} / \mathrm{ms}\right)$. 


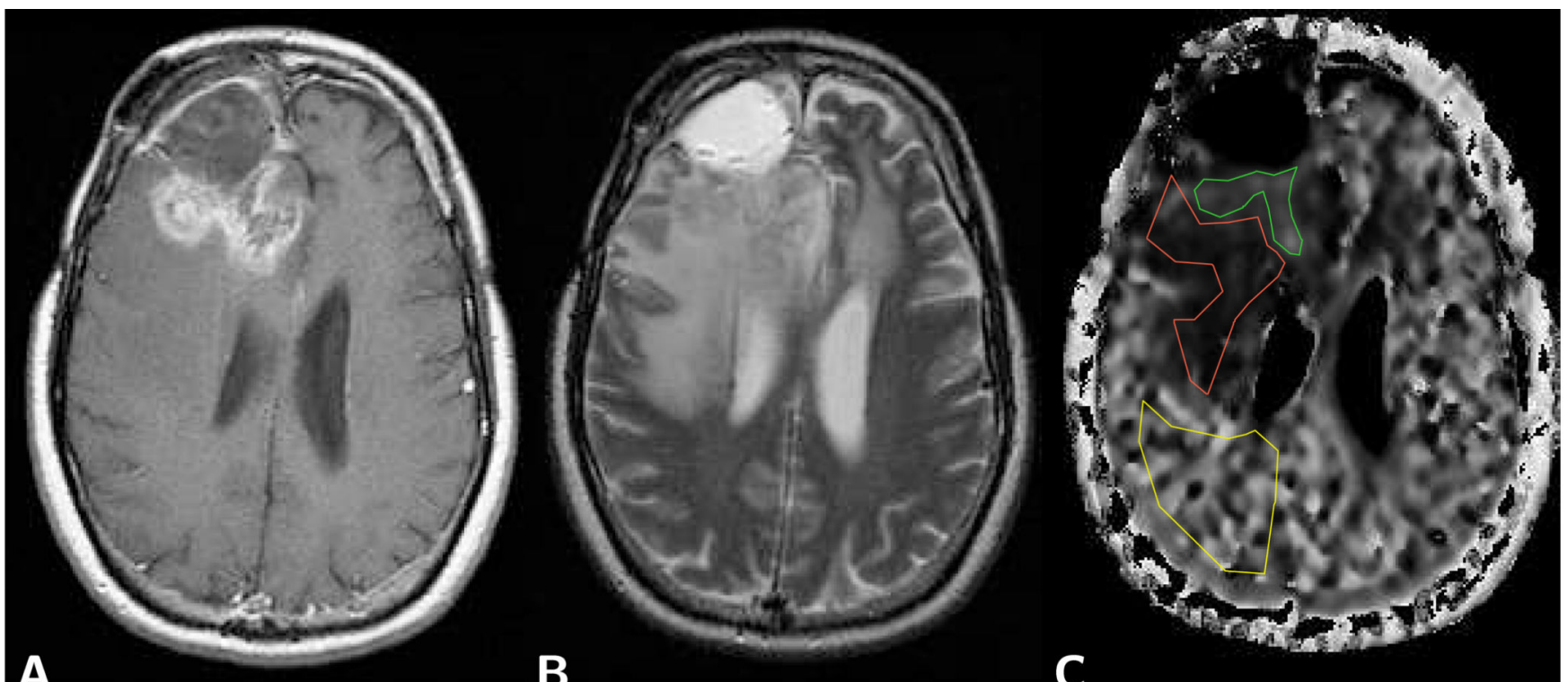

$\mathbf{A}$

B

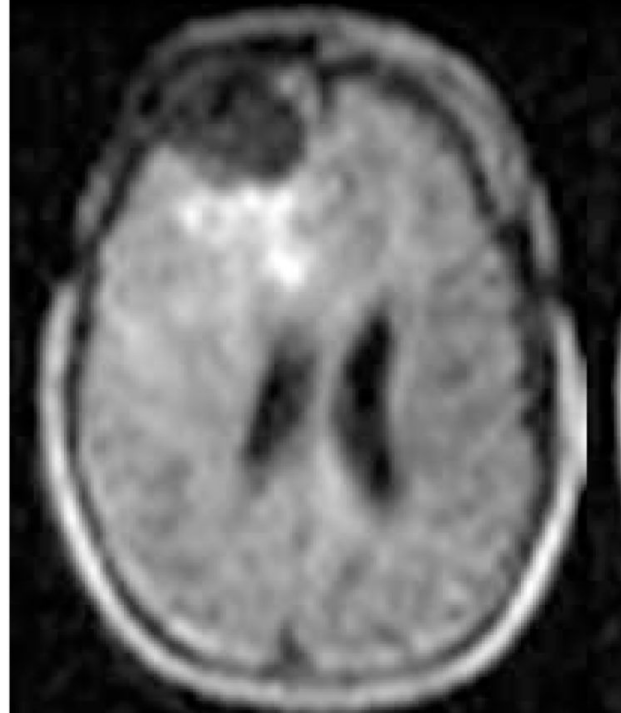

D

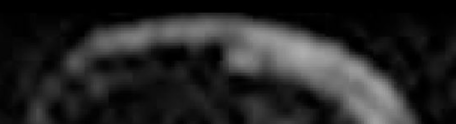

Figure 2.

Axial brain images of a frontal glioblastoma with postoperative cyst formation in a 38 year old male patient. A) $\mathrm{T}_{1}$-weighted post-contrast spin-echo image (TR $600 \mathrm{~ms} / \mathrm{TE} 25 \mathrm{~ms}$ ) predominantly shows the tumor marginal area and not the solid part of the tumor. $\mathrm{B}$ ) $\mathrm{T}_{2^{-}}$ weighted spin-echo image (TR 3,600 ms/TE $98 \mathrm{~ms}$ ) shows a bright cyst and edema-related hyperintensity. C) Computed slow diffusion component size image with overlaid ROIs for tumor (green, $f_{s}=0.23$ ), edema (red, $f_{s}=0.11$ ), and normal appearing brain tissue (yellow, $f_{s}=0.35$ ). D) LSDI image with a $b$-factor of $1,000 \mathrm{~s} / \mathrm{mm}^{2}$ shows hyperintensity within the tumor. E) LSDI image with a high $b$-factor of $3,000 \mathrm{~s} / \mathrm{mm}^{2}$ also shows hyperintensity within the tumor. F) Very high diffusion-weighted LSDI image with a $b$-factor of $5,000 \mathrm{~s} / \mathrm{mm}^{2}$ exhibits signal above the noise threshold for all tissues. Extraordinary high residual signal, despite high diffusion weighting, is observed in the solid part of the tumor. LSDI images were all obtained with a single diffusion encoding direction and the following scan parameters: $64 \times 48$ imaging matrix interpolated to a $25 \times 192$ matrix, $220 \mathrm{~mm} \times 165 \mathrm{~mm}$ field 
of view, $7.3 \mathrm{~mm}$ slice thickness, $2,040 \mathrm{~ms}$ TR, $94 \mathrm{~ms} \mathrm{TE}, 16 b$-factors. The diffusion values measured with conventional diffusion imaging $\left(b=1,000 \mathrm{~s} / \mathrm{mm}^{2}\right)$ were $1.10 \mu \mathrm{m}^{2} / \mathrm{ms}$ for tumor and $0.74 \mu \mathrm{m}^{2} / \mathrm{ms}$ for normal appearing white matter. 


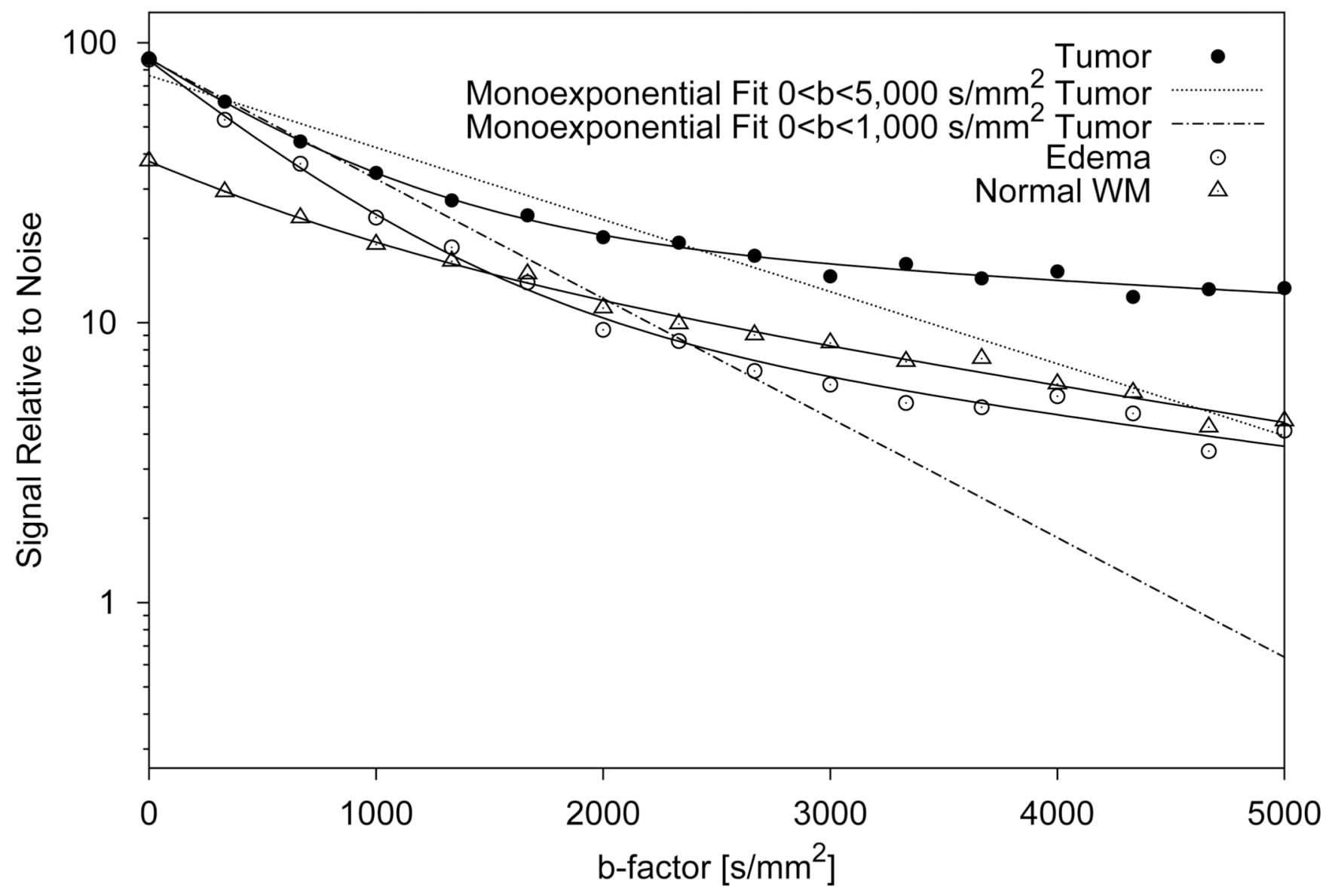

Figure 3.

Plot of diffusion-attenuated signal vs $b$-factor for individual pixels in a glioblastoma tumor, normal white matter (WM) and edematous tissue. The solid lines show biexponentially fitted signal decay curves. For tumor tissue, monoexponential fits are shown for the whole diffusion weighting range $\left(0-5,000 \mathrm{~s} / \mathrm{mm}^{2}\right.$, dotted line) and for the normal diffusion weighting range $\left(0-1,000 \mathrm{~s} / \mathrm{mm}^{2}\right.$, dash-dotted line). Without diffusion weighting, tumor and edema can not be distinguished and exhibit higher signal than normal white matter. With increasing diffusion weighting, the signal of the edematous tissue decreases more rapidly than the signal of the other tissues and approaches the signal level of normal white matter. Tumor tissue exhibits the slowest signal decay and shows the highest residual signal at very high $b$-factors. On the logarithmic signal scale, the deviation of the signal decay curves from a straight-line monoexponential decay is obvious. 

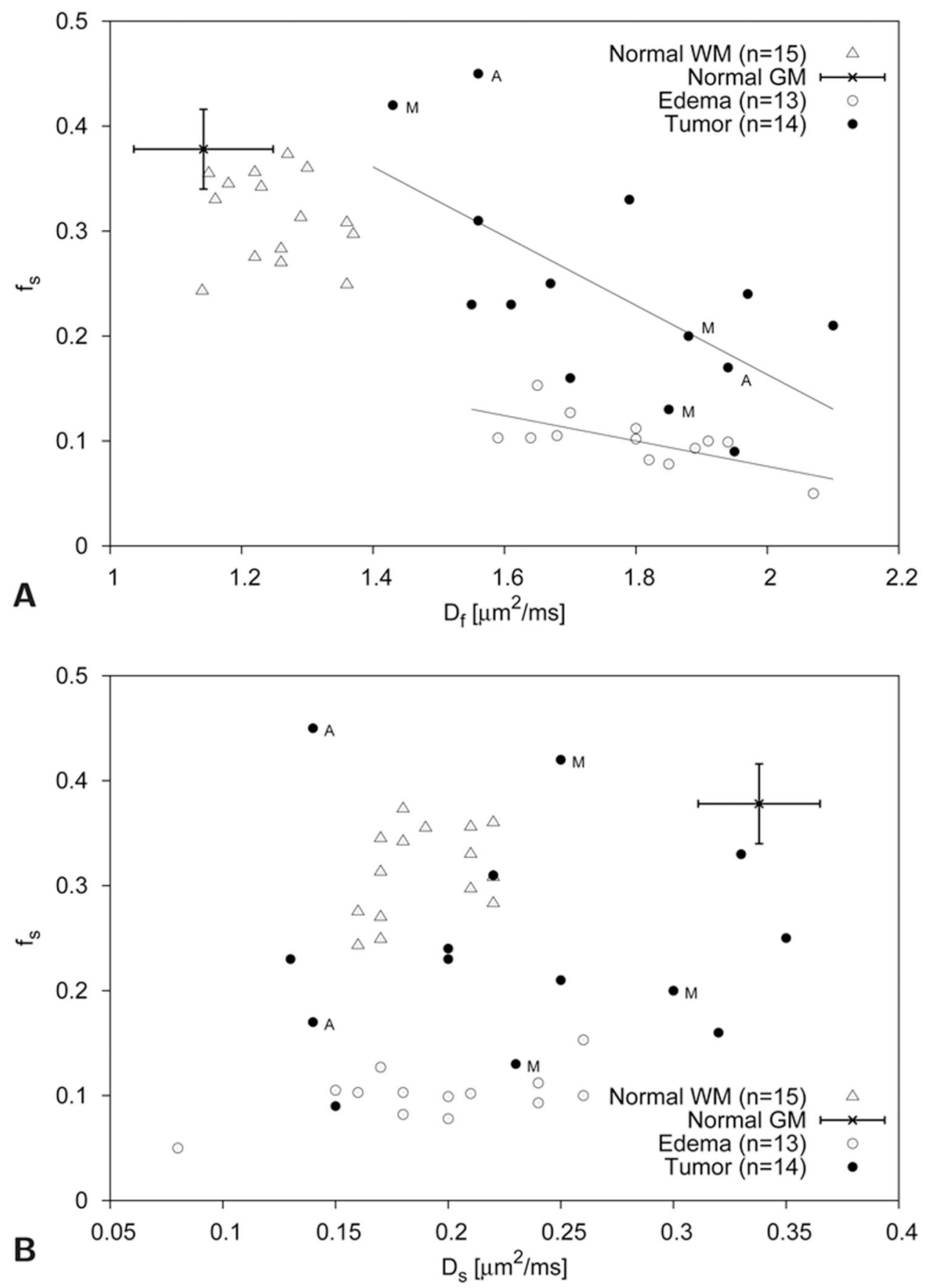

Figure 4.

Scatter plots of slow diffusion component size fraction $f_{s}$ vs fast diffusion coefficient $D_{f}$ (top graph) and slow diffusion coefficient $D_{s}$ (bottom graph) ROI values measured with singledirection diffusion encoding in fourteen tumor patients (nine WHO grade IV glioblastomas, two WHO grade III astrocytomas and three metastases) [7]. Astrocytomas and metastatic tumors are indicated by the letter A and M, respectively. Representative gray matter (GM) values obtained in an other study [63] are also shown. Normal white matter (WM), gray matter, and edematous tissue can readily be separated with these parameters. With the slow diffusion component size fraction $f_{s}$ and the fast diffusion coefficient $D_{f}$, tumor tissue can also clearly be distinguished from normal white and gray matter. Some overlap is observed 
between tumor tissue values and edematous tissue values. Indicated with linear least square fits for both tumor $(r=-0.64)$ and edematous $(r=-0.69)$ tissue is the obvious trend towards lower slow diffusion component size fractions $f_{s}$ at higher $D_{f}$ values. Separation of different tumor types based on these diffusion parameters seems difficult, although more samples would be needed to fully address this issue. 


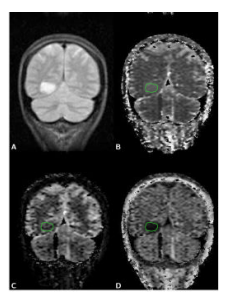

\section{Figure 5.}

Coronal brain images of a 46 year old female patient with a low grade oligodendroglioma (WHO grade II, see Case 2 in Table 3). A) $\mathrm{T}_{2}$-weighted image of LSDI scan obtained with normal diffusion weighting (TR 2,673 ms/TE $66 \mathrm{~ms}$ ) shows an enhancing lesion. On the other images the corresponding area is indicated by the green ROI outline. B) Map of the mean fast diffusion coefficient $D_{f}$ obtained from high- $b$ LSDI trace data (scan parameter: $128 \times 48$ imaging matrix interpolated to a $256 \times 192$ matrix, $220 \mathrm{~mm} \times 165 \mathrm{~mm}$ field of view, 6 $\mathrm{mm}$ slice thickness, 2,430 ms TR, and $96 \mathrm{~ms}$ TE, $16 b$-factors). Within the tumor, $D_{f}$ equals $1.47 \mu \mathrm{m}^{2} / \mathrm{ms}$ and is evidently slightly higher than the $D_{f}$ of the surrounding tissue. C) Map of the mean slow diffusion coefficient $D_{s}$ shows a clear dissociation between white and gray matter. $D_{s}$ within the tumor is $0.19 \mu \mathrm{m}^{2} / \mathrm{ms}$ and not distinctly different from the $D_{s}$ of surrounding white matter. D) On the map of the mean slow diffusion coefficient component size fraction $f_{s}$ the tumor area appears hypointense $\left(f_{s}=0.09\right)$. Line artifacts visible in the area of the cerebellum are caused by motion-related signal loss. 


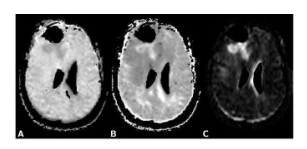

Figure 6.

Images computed from the patient diffusion data shown in Fig. 2. A) Map of the parameter $\alpha$ obtained with a stretched exponential fit [52]. Compared to normal brain tissue, tumor tissue appears hypointense and edematous tissue slightly hyperintense. B) Map of excess kurtosis $K$ obtained with a fit to a second order polynomial in $b$ [54,61]. Compared to normal brain tissue, tumor tissue appears hyperintense and edematous tissue hypointense. White matter tracts running orthogonal to the diffusion encoding direction also appear hyperintense. C) Computed $\chi^{2}$ error map of the monoexponential fit to the diffusion related signal decay reveals hyperintensity of the solid part of the tumor and slightly higher intensity within the edematous tissue. Other areas of hyperintensity are due to partial volume effects in voxels with non-uniform tissues or fluid content. For representative values of individual pixels within the different tissues for each analysis method applied see Table 2. 


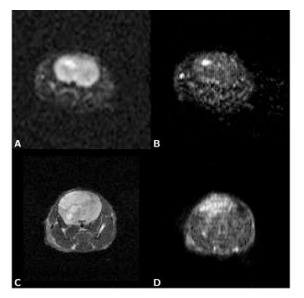

\section{Figure 7.}

Image data of mouse brain with human U-87 tumor $(30 \times 30 \mathrm{~mm}$ sub-images shown). Trace diffusion image data shown in A) and B) was obtained with LSDI at 3 Tesla $(128 \times 64$ matrix interpolated to a $256 \times 128$ matrix, $60 \times 30 \mathrm{~mm}$ FOV, $1.5 \mathrm{~mm}$ slice thickness, 3,726 ms TR, 89 ms TE, $32 b$-factors, no signal averaging). $\mathrm{T}_{2}$-weighted data and trace diffusion image data shown in C) and D) was obtained with 2D-FT imaging and LSDI at 4.7 Tesla (LSDI: $256 \times 128$ matrix interpolated to a $256 \times 256$ matrix, $40 \times 40 \mathrm{~mm}$ FOV, $1.5 \mathrm{~mm}$ slice thickness. 4,266 ms TR, $36 \mathrm{~ms}$ TE, 32 -factors, no signal averaging). A) On the $\mathrm{T}_{2}$-weighted LSDI image, the tumor area appears hyperintense (U-87 tumors are known to present insignificant edema). B) On the $\chi^{2}$ error parameter map, the tumor area also appears hyperintense (contrast ratio between tumor and normal tissue: 3.8 ). A second, smaller bright spot on the left side of the image, outside of the brain, is attributed to inflowing blood within a large vessel. C) A larger hyperintense area can be seen on the $\mathrm{T}_{2}$-weighted $2 \mathrm{D}$-FT image (TR $2590 \mathrm{~ms} / \mathrm{TE} 48 \mathrm{~ms}$ ) of a later stage in a different animal. D) The same area appears also appears hyperintense on the corresponding $\chi^{2}$-map (tumor/normal tissue contrast ratio: 2.4 ). 


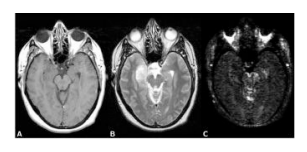

Figure 8.

Axial brain images of a 47 year old female patient with a right temporal low grade astrocytoma (grade I). A) The post-contrast T1-weighted spin-echo image (TR 650/TE 14) shows no enhancement at the location of the tumor. B) The T2-weighted spin-echo image (TR 3,450/TE 98) demonstrates the tumor lesion. C) On the $\chi^{2}$ error parameter map, similarly as on the $\mathrm{T}_{1}$-weighted image, the tumor appears isointense with the surrounding normal tissue. Artifactual high image intensities due to intermittent motion-related signal loss, however, are present in the orbital cavity. LSDI high- $b$ scan parameters are the same as those presented in Fig. 2. 


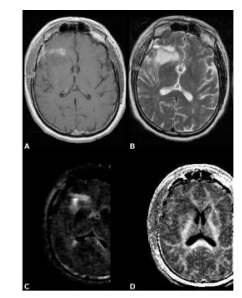

\section{Figure 9.}

Axial brain images of a 49 year old male patient with an oligodendroglioma WHO grade II (see Case 1 in Table 3). A) $\mathrm{T}_{1}$-weighted post-contrast spin-echo image (TR $750 \mathrm{~ms} / \mathrm{TE} 14$ $\mathrm{ms}$ ) shows a small enhancing lesion. B) The $\mathrm{T}_{2}$-weighted spin-echo image (TR 3,900 ms/TE $98 \mathrm{~ms}$ ) presents a larger area of hyperintensity. C) On the $\chi^{2}$ error parameter map, the area of hyperintensity exceeds the area of enhancement apparent on the $\mathrm{T}_{1}$-weighted image. LSDI high- $b$ scan parameters are the same as already presented in Fig. 2. D) FA map obtained with conventional LSDI tensor imaging shows extensive nerve fiber tract destruction within the area of hyperintensity documented on the $T_{2}$-weighted image and the $\chi^{2}$ error parameter map. Evidently tumor growth extends beyond the area of enhancement visible on the $\mathrm{T}_{1^{-}}$ weighted image. 


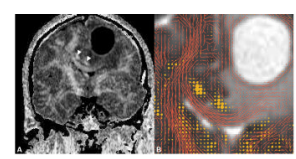

Figure 10.

Coronal images of a giant cell astrocytoma with cyst formation in a 51 year old male patient. A) The LSDI FA map reveals a marked lateral shift of the corpus callosum and the cingulum tracts (arrows). B) ADC map showing an enlarged area with overlaid glyphs that represent the primary diffusion eigenvector scaled by the FA of the respective voxel. The in-plane component of the scaled primary diffusion eigenvector is depicted with short line segments and the out-of plane component by dots of different sizes. A widening, without apparent fiber destruction, of the left half of the corpus callosum can be discerned. In the immediate surrounding of the cyst, fiber structures appear to be intact, but severely distorted. The ADC value within the edematous part of the corpus callosum equals $1.18 \mu \mathrm{m}^{2} / \mathrm{ms}$ and within the cystic lesion $2.82 \mu \mathrm{m}^{2} / \mathrm{ms}$. 


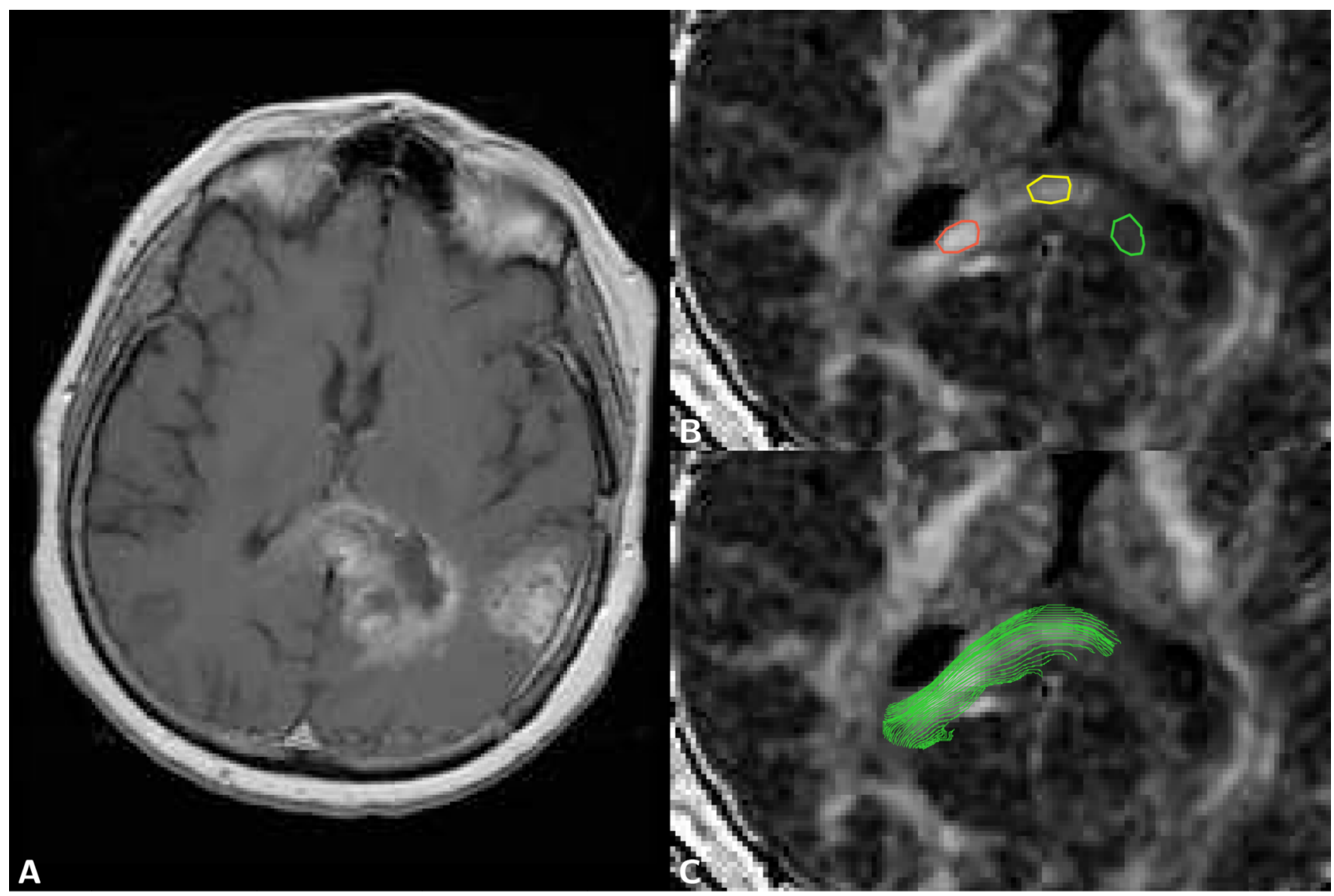

Figure 11.

Axial brain images of a 57 year old female patient with a multifocal glioblastoma. A) The $\mathrm{T}_{1}$-weighted post-contrast spin-echo image (TR $750 \mathrm{~ms} / \mathrm{TE} 14 \mathrm{~ms}$ ) shows two lesions, one of them with invasion into the splenium of the corpus callosum. B) Detail of FA map with three regions of interest (ROI) drawn in the splenium of the corpus callosum (FA values: red ROI 0.65, yellow ROI 0.46, green ROI 0.20). C) Same FA map as shown in B) with overlaid in-plane fiber tracking path, documenting the presence of intact fibers in the tumor-invaded splenium. 


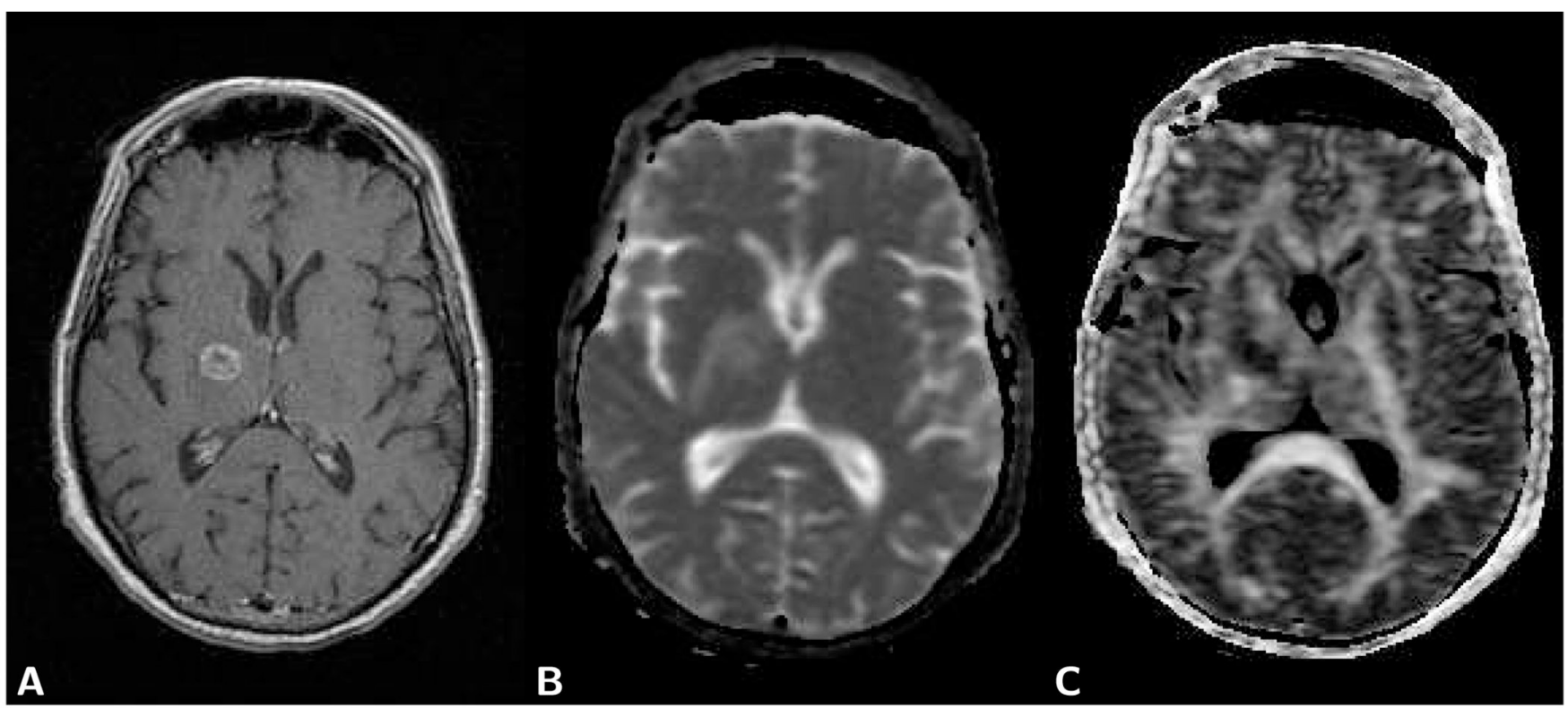

Figure 12.

Axial brain images of a 57 year old male patient with lung tumor metastasis. A) The axial $\mathrm{T}_{1}$-weighted post-contrast spin-echo image (TR $700 \mathrm{~ms} / \mathrm{TE} 14 \mathrm{~ms}$ ) shows a small lesion with an enhancing rim within the internal capsule. B) On the ADC map elevated diffusion is evident within the tumor and surrounding edema. (tumor ADC: $1.11 \mu \mathrm{m}^{2} / \mathrm{ms}$; normal appearing white matter ADC: $\left.0.71 \mu \mathrm{m}^{2} / \mathrm{ms}\right)$. C) On the FA map the tumor lesion is clearly discerned as an area with low anisotropy (tumor FA: 0.08; contra-lateral side internal capsule FA: 0.47). 
Table 1

Diffusion values of normal and pathological tissues in the brain.

\begin{tabular}{|c|c|}
\hline Normal Brain Tissue & $\mathrm{ADC} \mu \mathrm{m}^{2} / \mathrm{ms}$ \\
\hline Normal White Matter [107] & $0.705 \pm 0.014$ \\
\hline Deep Gray Matter [108] & $0.75 \pm 0.03$ \\
\hline Neuroepithelial Tumors & $\mathrm{ADC} \mu \mathrm{m}^{2} / \mathrm{ms}$ \\
\hline WHO grade I, Dysembryoplastic Neuroepithelial Tumor [18] & $2.546 \pm 0.135$ \\
\hline WHO grade I, Pilocytic Astrocytoma [18] & $1.659 \pm 0.260$ \\
\hline WHO grade II, Diffuse Astrocytoma [18] & $1.530 \pm 0.148$ \\
\hline WHO grade II, Oligodendroglioma [18] & 1.455 \\
\hline WHO grade II, Ependymoma [18] & $1.230 \pm 0.119$ \\
\hline WHO grade III, Anaplastic Astrocytoma [18] & $1.245 \pm 0.153$ \\
\hline WHO grade III, Anaplastic Oligodendroglioma [18] & $1.222 \pm 0.093$ \\
\hline WHO grade III, Anaplastic Ependymoma [18] & $1.103 \pm 0.101$ \\
\hline WHO grade IV, Glioblastoma [18] & $1.079 \pm 0.154$ \\
\hline WHO grade IV, PNET [18] & $0.835 \pm 0.122$ \\
\hline WHO grade IV, Medulloblastoma [23] & $0.66 \pm 0.15$ \\
\hline Other Brain Tumors & $\mathrm{ADC} \mu \mathrm{m}^{2} / \mathrm{ms}$ \\
\hline Chraniopharyngioma [18] & $1.572 \pm 0.210$ \\
\hline Schwannoma [18] & $1.384 \pm 0.140$ \\
\hline Epidermoid [18] & $1.263 \pm 0.174$ \\
\hline Germ Cell Tumor [18] & $1.189 \pm 0.175$ \\
\hline Metastatic Tumor [18] & $1.149 \pm 0.192$ \\
\hline Pituitary Adenoma [18] & $1.121 \pm 0.202$ \\
\hline Typical Meningeoma [109] & $1.17 \pm 0.21$ \\
\hline Atypical/Malignant Meningeoma [109] & $0.75 \pm 0.21$ \\
\hline Malignant Lymphoma [18] & $0.725 \pm 0.192$ \\
\hline Secondary Changes and Other Pathologies & $\mathrm{ADC} \mu \mathrm{m}^{2} / \mathrm{ms}$ \\
\hline Vasogenic (Peritumoral) Edema [19] & $1.30 \pm 0.11$ \\
\hline Peritumoral Edema (High-Grade Glial Tumors) [17] & $1.825 \pm 0.115$ \\
\hline Cytotoxic (Ischemic) Edema [19] & $1.04 \pm 0.05$ \\
\hline Cystic/Necrotic Tumor Areas [38] & $2.70 \pm 0.31$ \\
\hline Abscess [38] & $0.65 \pm 0.16$ \\
\hline Acute Stroke [110] & $0.401 \pm 0.143$ \\
\hline
\end{tabular}


$\stackrel{9}{9}$

苞

일

$\Xi \frac{50}{5}$

产 空

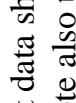

䒕

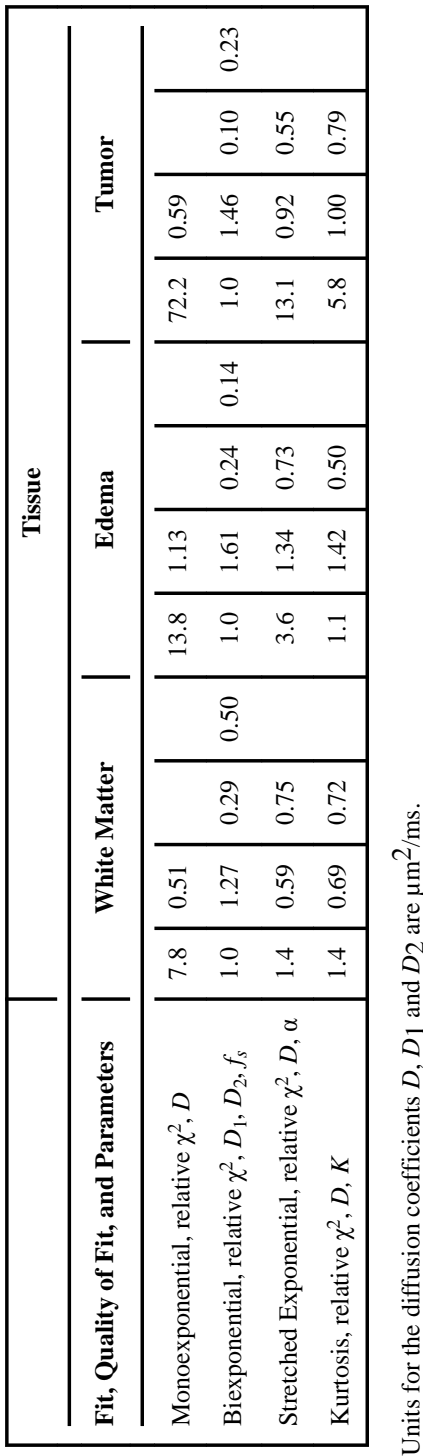

NMR Biomed. Author manuscript; available in PMC 2011 August 1. 


\section{Table 3}

Biexponential diffusion parameters of normal and pathological tissues.

\begin{tabular}{|c|c|c|c|c|}
\hline Normal Brain Tissue & $D_{f}\left[\mu \mathrm{m} / \mathrm{ms}^{2}\right]$ & $D_{s}\left[\mu \mathrm{m}^{2} / \mathrm{ms}\right]$ & $f_{f}[]$ & $f_{s}[]$ \\
\hline Internal Capsule WM [63] & $1.215 \pm 0.024$ & $0.183 \pm 0.009$ & $0.637 \pm 0.020$ & $0.363 \pm 0.020$ \\
\hline Frontal White Matter [63] & $1.155 \pm 0.046$ & $0.125 \pm 0.014$ & $0.699 \pm 0.050$ & $0.301 \pm 0.050$ \\
\hline Cortical Gray Matter [63] & $1.142 \pm 0.106$ & $0.338 \pm 0.027$ & $0.622 \pm 0.038$ & $0.378 \pm 0.038$ \\
\hline Thalamus [63] & $1.320 \pm 0.164$ & $0.271 \pm 0.040$ & $0.617 \pm 0.069$ & $0.383 \pm 0.069$ \\
\hline Pathological Brain Tissue & $D_{f}\left[\mu \mathrm{m}^{2} / \mathrm{ms}\right]$ & $D_{s}\left[\mu \mathrm{m}^{2} / \mathrm{ms}\right]$ & $f_{f}[]$ & $f_{s}[]$ \\
\hline Tumor (WHO Grade III and IV, Metastasis) [7] & $1.75 \pm 0.20$ & $0.23 \pm 0.07$ & $0.76 \pm 0.10$ & $0.24 \pm 0.10$ \\
\hline Tumor Case 1 (WHO Grade II, Low Grade Oligodendroglioma) & 1.85 & 0.22 & 0.83 & 0.17 \\
\hline Tumor Case 2 (WHO Grade II, Low Grade Oligodendroglioma) & 1.47 & 0.19 & 0.91 & 0.09 \\
\hline Tumor Case 3 (WHO Grade I, Low Grade Astrocytoma) & 1.64 & 0.17 & 0.88 & 0.12 \\
\hline Tumor Case 4 (WHO Grade I, Ganglioglioma) & 1.46 & 0.37 & 0.87 & 0.13 \\
\hline Peritumoral Edema [7] & $1.80 \pm 0.14$ & $0.20 \pm 0.05$ & $0.90 \pm 0.02$ & $0.10 \pm 0.02$ \\
\hline Peritumoral Edema [70] & $1.61 \pm 0.35$ & $0.23 \pm 0.085$ & $0.888 \pm 0.05$ & $0.112 \pm 0.05$ \\
\hline Stroke [72] & $1.356 \pm 0.257$ & $0.224 \pm 0.081$ & $0.491 \pm 0.109$ & $0.509 \pm 0.109$ \\
\hline Rat-Paw Muscle & $D_{f}\left[\mu \mathrm{m}^{2} / \mathrm{ms}\right]$ & $D_{s}\left[\mu \mathbf{m}^{2} / \mathrm{ms}\right]$ & $f_{f}[]$ & $f_{s}[]$ \\
\hline Normal [71] & $1.3 \pm 0.04$ & $0.16 \pm 0.05$ & $0.84 \pm 0.04$ & $0.16 \pm 0.04$ \\
\hline Edema [71] & $2.0 \pm 0.12$ & $0.27 \pm 0.03$ & $0.89 \pm 0.03$ & $0.11 \pm 0.03$ \\
\hline
\end{tabular}

